\title{
eCooking: Challenges and Opportunities from a Consumer Behaviour Perspective
}

\author{
Jon Leary ${ }^{1,2, *}$, Bridget Menyeh ${ }^{2}$, Vimbai Chapungu ${ }^{1}$ and Karin Troncoso ${ }^{2}$ \\ 1 Gamos Ltd., 231 King's Rd, Reading RG1 4LS, UK; vimbai@gamos.org \\ 2 Geography and Environment, School of Social Sciences and Humanities, Loughborough University, \\ Loughborough LE11 3TU, UK; B.O.Menyeh@lboro.ac.uk (B.M.); k.s.troncoso@lboro.ac.uk (K.T.) \\ * Correspondence: j.leary@lboro.ac.uk
}

Citation: Leary, J.; Menyeh, B.; Chapungu, V.; Troncoso, K. eCooking Challenges and Opportunities from a Consumer Behaviour Perspective. Energies 2021, 14, 4345. https:// doi.org/10.3390/en14144345

Academic Editor: David Borge-Diez

Received: 26 May 2021

Accepted: 6 July 2021

Published: 19 July 2021

Publisher's Note: MDPI stays neutral with regard to jurisdictional claims in published maps and institutional affiliations.

Copyright: (c) 2021 by the authors. Licensee MDPI, Basel, Switzerland. This article is an open access article distributed under the terms and conditions of the Creative Commons Attribution (CC BY) license (https:// creativecommons.org/licenses/by/ $4.0 /)$.

\begin{abstract}
New opportunities are opening for electric cooking (eCooking) as a cost-effective, practical and desirable solution to the twin global challenges of clean cooking and electrification. Globally, momentum is building behind the transformative potential of eCooking to achieve a range of environmental and social impacts. However, cooking is a complex, culturally embedded practice, that results in an array of behavioural change challenges that must be understood and overcome for these new opportunities to translate into impact at scale. The Modern Energy Cooking Services (MECS) programme was designed to explore this space and pilot innovative new eCooking services with the potential to rapidly scale. This paper reflects upon the programme's key learnings to date on the behavioural change dimension of eCooking. It consolidates what we now know on the subject and highlights the gaps that remain, where further investigation is needed. The evidence shows that the uptake of eCooking can be hindered by (often false) perceptions around cost, taste and safety, the high cost and steep learning curve for new appliances, the lack of awareness/availability/aftersales service for energy-efficient appliances and the reluctance of male decision-makers to authorise appliance purchases. However, it also shows that the convenience and potential cost savings offered by energy-efficient appliances can offer an aspirational cooking experience and that uptake could be driven forward rapidly by urbanisation and changing lifestyles.
\end{abstract}

Keywords: electric cooking; clean cooking; perceptions; appliances; consumer behaviour

\section{Introduction}

Two-point-eight billion people still rely on polluting fuels and technologies to cook most of their meals, however less than 800 million are now without access to electricity [1]. These statistics are usually quoted separately, however examining them together reveals a potentially transformative opportunity for the two billion people who now have access to some form of electricity, yet still cook with polluting fuels and technologies: cooking with electricity. In 2014, the WHO (World Health Organisation) published their Indoor Air Quality (IAQ) guidelines [2], highlighting the importance of transitioning away from the use of polluting fuels (biomass and kerosene) towards clean fuels, such as gas and electricity, to significantly reduce exposure to indoor air pollution. The use of polluting fuels, in particular, solid biomass, for cooking is also deeply intertwined with other development challenges, such as poverty, gender, forest degradation and climate change.

The Modern Energy Cooking Services (MECS) programme was designed to bring together the clean cooking and electrification sectors to explore the emerging opportunities around cooking with electricity [3]. For decades, these two areas have been treated as two separate problems, with the clean cooking sector rarely considering electricity as a viable option and the electrification sector percieving cooking loads as outside of their scope. However, electricity grids are expanding rapidly and growing stronger in many areas of the Global South, meanwhile mini-grids and solar home systems are extending access beyond their reach. What is more, new energy storage technologies can buffer fluctuations 
in unreliable electricity supplies enabling electric appliances to deliver cooking services when people want to cook, not just when high quality power happens to be available $[4,5]$.

Initial indications show that electric cooking, or eCooking, has the potential to rapidly scale as an aspirational solution for many consumers currently struggling to cook with biomass and other polluting fuels [4]. Initial research findings have also indicated that unlike many Improved CookStoves (ICS), which have struggled to attain acceptability amongst consumers, modern energy-efficient electric appliances that fit well with local cooking culture can be highly desirable to consumers [6,7]. This offers the potential to follow in the footsteps of the mobile phone, mobile money and solar lighting revolutions that have already swept across the Global South, where transformative change was achieved by unlocking latent consumer demand for aspirational services with technological and business model innovations.

Nonetheless, to take advantage of these emerging opportunities, it is imperative to fully understand consumer behaviour, not just needs, but perhaps more importantly, aspirations. Consumer behaviour is shaped by an array of processes internal and external to the individual; meaning that changing behaviour is complex [8-10]. As a result, the ICS sector has faced a myriad of challenges whilst attempting to transition consumers towards less polluting cooking options. Many important lessons have been learned, which can inform the rollout of eCooking. Undoubtedly, eCooking also presents new challenges, however it also offers fresh solutions to old challenges. For example, the upfront cost of cooking devices is a well-documented barrier that has prevented many people from accessing ICS [11]. However, eCooking opens new opportunities for innovative financing mechanisms, such as on-bill financing mechanisms that enable electricity service providers to sell appliances on credit to their existing customers, or appliances with locking mechanisms for pay-as-you-go (PAYG) business models that enable appliance distributors to reach lower income consumers. An important lesson from ICS implementation programmes is that a persistent focus on technology often comes at the expense of the behaviour change elements necessary to achieve the intended behavioural outcome. Thus, this paper seeks to explore the challenges and opportunities presented by eCooking from a consumer behaviour perspective. It explores the compatibility of a range of eCooking solutions with current and aspirational cooking practices of key consumer groups across the Global South. It builds upon previous work by Brown and Leary [12] that laid the foundation for what has now become the MECS programme's Behavioural Change Workstream. The paper aims to inform researchers and practitioners working directly on the MECS programme, as well as those in the converging clean cooking and electrification sectors more broadly.

The paper aims to answer the following key research questions:

- What are the key behavioural change challenges and opportunities for eCooking?

- Which delivery approaches might be best suited to address these challenges and leverage the opportunities?

- What are the key behavioural research gaps in the emerging field of eCooking?

Using a literature review approach, the paper distils the key learnings relating to consumer behaviour and eCooking from the literature produced by the MECS programme to date. Many studies have presented similar literature reviews in the clean cooking sector; however, none have yet focused specifically on eCooking. For example, Quinn et al.'s [13] systematic review of case studies examining clean cooking programme rollouts, observed 11 projects in 11 countries. 5 of the 11 focus on LPG, the others comprise ethanol (2), biogas (2), and biomass pellets and briquettes (2), but none on eCooking. Puzzolo et al. [14] reviewed 44 studies on clean fuels, 17 on biogas, 12 on LPG, 9 on solar cookers, 6 on alcohol fuels, but also found none on eCooking. ESMAP's [15] systematic review of barriers and drivers for modern energy cooking services reviewed a total of 91 fully coded and 47 partly-coded articles and found just 1 that partially focused on eCooking.

By focusing on eCooking, this paper fills a gap in the literature, providing muchneeded insight on this new sector that holds the potential to support all four pillars of SDG7's goal of universal access to energy by 2030. Until recently, eCooking has not been 
seen as a viable option in the renewable energy, energy efficiency, clean cooking and electricity access sectors. As a result, this paper advocates for eCooking to draw attention to the emerging opportunities where eCooking could make a valuable contribution to the energy sector in developing countries.

\section{Materials and Methods}

This paper draws together the collective experience to date from across the MECS programme by reviewing project reports and academic papers published by MECS partners, as well as interactions with MECS Country Partners in the programme's 15 Priority Countries. The literature review was carried out by MECS researchers and involved assembling a database with the key learnings from each source, distilled and grouped thematically. Puzzolo et al.'s [14] systematic review of barriers and drivers for clean cooking was used as a framework to structure the emerging insights into seven domains:

1. Fuel and technology characteristics

2. Household and setting characteristics

3. Knowledge and perceptions

4. Financial, tax and subsidy

5. Market development

6. Regulation, legislation and standards

7. Programmatic and policy mechanisms

Puzzolo et al.'s [14] literature review did not include eCooking, therefore by using their framework, direct comparisons can be made with their results for other clean cooking fuels. An analysis was then conducted on the key findings emerging from each theme to collate the key learning points to date in each of these seven areas, highlighting the gaps where further research, innovation and piloting is needed. The paper concludes with suggestions for further studies that could be carried out to fill these gaps by drawing upon behaviour change theory and approaches used in the clean cooking and electrification sectors.

\subsection{Overview of MECS Programme Literature}

MECS is a broad programme consisting of a diverse array of actors, however the majority of consumer studies within the programme have been carried out by four major groups:

- Challenge Fund Winners;

- Country Partners (Kenya, Tanzania, Zambia, Uganda, Ethiopia, Rwanda, Ghana, Nigeria, Gambia, Malawi, Cameroon, Bangladesh, Myanmar, Nepal, Cambodia);

- UK Universities and Innovators; and

- $\quad$ The World Bank's Energy Sector Management Assistance Programme (ESMAP).

MECS Challenge Fund Winners are predominantly NGOs and private sector organisations who have been supported by grant funding from the MECS programme to explore the viability of delivering eCooking as part of their suite of services. MECS Country Partners coordinate activities in their country, carrying out strategic research and stakeholder engagement to explore context-specific opportunities. A consortium of universities and innovators in the UK have been working collaboratively to apply their interdisciplinary expertise to carry out early-stage research on specific aspects of eCooking. Finally, the ESMAP team draw upon their global network and deep insight on energy markets to identify and implement pathways to scale, with the aim of leveraging the World Bank's International Development Assistance (IDA) programme to support larger scale piloting of eCooking.

This review also draws together the key findings from the studies that laid the foundation for the MECS programme:

'Innovate' - A detailed market study for battery-supported eCooking in Zambia, Tanzania and Myanmar supported by UK Aid via Innovate UK's Energy Catalyst [16-18]. 
'LCT'-An exploration of a range of low-cost technologies for the bottom of the pyramid consumers in Kenya and Bangladesh supported by UK Aid via the USES (Understanding Sustainable Energy Solutions) programme [6,19].

\subsection{Behaviour Change Techniques (BCTs) and Theoretical Frameworks}

The paper concludes by exploring how further insights could be gained from behaviour change theory. An overview of the most relevant theoretical frameworks on the diffusion of innovations and consumer behaviour that can help reveal the motivations behind cooking behaviours and identify barriers and opportunities to change is presented in Appendix A. Specifically, Roger's Diffusion of Innovations Theory [20]; the Theories of Reasoned Action (TRA) [21] and Planned Behaviour (TPB) [22]; the Behaviour Change Wheel [23]; and a review of BCTs in the clean cooking sector [24].

\section{Results}

This section presents and discusses the key learning points distilled from the literature review structured according to Puzzolo et al.'s seven domains.

\subsection{Fuel and Technology Characteristics}

The characteristics of electricity as a cooking fuel varies considerably, as a wide range of electricity supply technologies and cooking appliances are now available. For example, cooking with an induction stove connected to an unlimited supply of reliable grid electricity offers a completely different experience to cooking with a highly insulated electric cooking device connected directly to solar panels [25-27]. This section seeks to draw together commonalities between this diverse array of technologies, as well as highlighting the opportunities and challenges unique to each.

\subsubsection{The Role of Energy-Efficient Appliances}

Early work on eCooking tended to focus on electric hotplates as the most viable appliance in developing country contexts $[12,28]$, however the role of energy-efficient appliances has become increasingly apparent [4,5]. Energy-efficient appliances can offer a more convenient modern cooking experience, whereas hotplates offer a similar user experience to a familiar charcoal stove. Hotplates have already been widely adopted in several Sub-Saharan African (SSA) contexts with high charcoal usage, such as Zambia [18]. However, cooking diaries in Kenya and Tanzania $[19,29]$ revealed a different set of cooking behaviours, as many households had already adopted LPG as a substitute for charcoal in urban areas. When participants were given the opportunity to cook with a hotplate, they preferred the fine manual control of heat levels and extra firepower of LPG. This highlights the need to compare the user experience of each eCooking appliance with the most popular fuels and devices currently in use in each context to highlight both the barriers and drivers for cooks to change their behaviour and consider adopting electricity into their fuel stack.

In early studies, MECS trialled energy-efficient appliances alongside hotplates and found that the former was much more popular $[19,29]$. As expected, cost savings from increased cooking efficiency were important to participants. However, these studies showed that the improved cooking experience, in particular, the convenience of automated cooking, was also highly attractive to cooks [19]. Automated electric cooking appliances control the cooking environment and switch off automatically, freeing up the cook's time to focus on other things. In comparison, even an LPG stove must be regularly monitored to ensure the food does not burn. Table 1 shows that a diverse range of energy-efficient eCooking appliances are now available, each presenting unique barriers and drivers for changing behaviour in the kitchen. Hotplates, LPG stoves, charcoal stoves and other cooking devices that heat an uninsulated pot from below waste a lot of energy through convection up the sides of the pot, evaporation via steam escaping and radiation from the sides of the pot. In contrast, the automation, insulation and pressurisation of appliances, such as rice cookers, Electric Pressure Cookers (EPCs) and insulated electric frying pans, 
can make them much efficient and convenient for specific food types $[6,17,30]$. As a result, cooks can spend more time relaxing, on other household chores, income-generating activities, self-care and family care [31]. Increased efficiency directly results in cost savings, which are a powerful incentive to encourage cooks to change their behaviour and adopt a new cooking device [4]. Insulation can also mitigate the effects of short blackouts and voltage instability [32], which can give cooks greater reassurance that they will be able to get dinner on the table without having to resort to another cooking fuel as backup. Insulation can also make the cook more comfortable in hot climates by keeping the heat inside the pot where it can cook the food instead of heating the cook [33].

Table 1. Summary of behavioural change challenges and opportunities for popular eCooking appliances.

\begin{tabular}{|c|c|c|}
\hline eCooking Appliance & Behavioural Change Challenges & Behavioural Change Opportunities \\
\hline Hotplate & 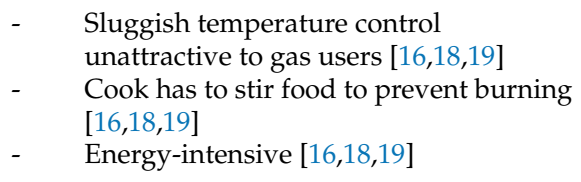 & $\begin{array}{l}\text { - } \quad \text { Similar User Experience (UX) for charcoal users (i.e., } \\
\text { uninsulated heating pot from below) [34] } \\
\text { - } \quad \text { Highly versatile }[16,18,19] \\
\text { - } \quad \text { The cook can see, smell and stir food while cooking }[16,18,19]\end{array}$ \\
\hline Oven & $\begin{array}{ll}\text { - } & \text { Very energy-intensive [35] } \\
\text { - } & \text { Can only bake/roast [35] }\end{array}$ & Similar UX in contexts where baking/roasting is popular [35] \\
\hline Induction stove & $\begin{array}{ll}\text { - } & \text { Difficult to cook flatbreads (e.g., chapati) } \\
& {[36]} \\
\text { - } & \text { Requires flat-bottomed steel utensils } \\
& {[16,17]} \\
\text { - } & \text { Cook has to stir food to prevent burning } \\
& {[16,17]} \\
\text { - } & \text { User interface can be confusing }[16,17]\end{array}$ & $\begin{array}{ll}\text { - } & \text { Highly versatile }[16,17] \\
\text { - } & \text { Similar UX for gas users (i.e., uninsulated heating pot from } \\
\text { below with ability to rapidly change heat levels) }[16,17] \\
\text { - } \quad \text { Cook can see, smell and stir food }[16,17] \\
\text { - } \quad \text { Safety - heats pan directly }[16,17] \\
\text { - } \quad \text { More energy-efficient than hotplate }[16,17]\end{array}$ \\
\hline Infra-red stove & $\begin{array}{ll}\text { - } & \text { Cook has to stir food to prevent burning } \\
\text { - } & \text { Energy-intensive [17] } \\
\text { - } & \text { User interface can be confusing [17] } \\
\text { - } & \text { Flat-bottomed utensils only [17] }\end{array}$ & 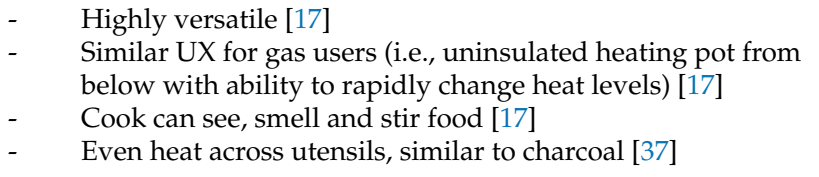 \\
\hline Kettle & $\begin{array}{l}\text { Water boiling only [29] } \\
\text { Single jug-shaped utensil only [29] }\end{array}$ & $\begin{array}{ll}\text { - } & \text { Very quick and efficient at boiling water [16] } \\
\text { - } & \text { Easy to multitask [16] } \\
\text { - } & \text { Simple to use [16] }\end{array}$ \\
\hline Microwave & $\begin{array}{l}\text { - } \quad \text { Steep learning curve [16] } \\
\text { - } \quad \text { Cannot see, smell or stir the food whilst } \\
\text { cooking [16] } \\
\text { - } \quad \text { Difficult to brown food [16] }\end{array}$ & $\begin{array}{ll}\text { - } & \text { Easy to reheat food directly on the plate [16] } \\
\text { - } & \text { Energy-efficient [16] } \\
\text { - } & \text { Easy to multitask [16] }\end{array}$ \\
\hline Rice cooker & $\begin{array}{ll}\text { - } & \text { Single flat-bottomed deep pot only [17] } \\
\text { - } & \text { Frying difficult [17] }\end{array}$ & $\begin{array}{ll}- & \text { Very simple to use [17] } \\
\text { - } & \text { Easy to multitask [17] } \\
\text { - } & \text { Cook can see, smell and stir food if the lid open [17] }\end{array}$ \\
\hline $\begin{array}{l}\text { Electric Pressure Cooker } \\
\text { (EPC) }\end{array}$ & $\begin{array}{ll}\text { - } & \text { Steep learning curve [6] } \\
\text { - } & \text { Single flat-bottomed deep pot only [6] } \\
\text { - } & \text { Pressure cooking often perceived as } \\
\text { unsafe }[6,18,19] \\
\text { - }\end{array}$ & $\begin{array}{l}\text { - } \quad \text { Big energy and time savings for most energy-intensive dishes } \\
{[6,30,38]} \\
\text { - } \quad \text { Multiple automated safety and control mechanisms }[6,39] \\
\text { - } \quad \text { Easy to multitask [6] } \\
\text { - } \quad \text { Cook can see, smell and stir food, except when pressurised } \\
\text { [17] }\end{array}$ \\
\hline $\begin{array}{l}\text { Insulated electric } \\
\text { frying pan }\end{array}$ & $\begin{array}{ll}\text { - } & \text { Single shallow pot only [17] } \\
\text { - } & \text { Boiling difficult [17] }\end{array}$ & $\begin{array}{l}\text { Round bottomed utensils useful for some types of frying [17] } \\
\text { Energy-efficient [17] }\end{array}$ \\
\hline
\end{tabular}

The EPC emerged from early research as a promising option, particularly in East Africa, where 'heavy foods' (foods that require boiling for more than an hour, e.g., beans), 
are frequently cooked $[6,19,30]$. EPCs can reduce electricity demand (and therefore cost) by up to $80 \%$ for the most energy-intensive dishes $[6,7,31]$ and up to $50 \%$ across the entire range of foods they can cook [4]. Importantly, the automated cooking experience offers the cook the opportunity to relax. As a result, many subsequent MECS field trials focused specifically on EPCs with the aim of understanding their role in facilitating the adoption of eCooking in different contexts $[31,40,41]$.

"I love the EPC—it's so easy to just throw everything in the pot. I leave it to do its thing whilst I go off and do mine".

"Cooking faster, saving money and keeping my kitchen and clothes clean. I love the freedom the EPC gives us-we can multitask, cook indoors and don't have to plan so far in advance for dishes like beans".

Cooks featured in the Kenya eCookBook [6].

It is important to recognise that there is a learning curve with EPCs $[6,18,19]$. Once people overcome this, they are often very satisfied with the new cooking experience. As a result, helping people get over this initial barrier clearly plays a pivotal role in facilitating adoption, for example, by demonstrating the key adaptations to cooking practices, such as pressure-cooking time and water quantity for each food type [6].

\subsubsection{The Evolution of eCooking Appliances for off-Grid and Weak-Grid Contexts}

A key area of innovation in MECS has been adapting eCooking appliances around the restrictions of the electricity supply system, whilst simultaneously adapting to the diverse requirements of everyday cooks in the Global South (Table 2). Most electric cooking appliances are designed for contexts where an unlimited supply of grid electricity is available $24 \mathrm{~h}$ a day. As a result, making eCooking accessible to those with access to unreliable grid electricity or who are completely off-grid has required the appliances to be redesigned around a more limited and unpredictable supply of electricity. Selecting and field trialling energy-efficient appliances that are well matched to local cooking culture has been a key first step for many partners $[30,38]$, however, some innovative projects have also sought to adapt appliance design to local cooking culture, for example, by adding menu options in local languages (e.g., Burn Manufacturing), or developing customised cooking algorithms for local foods (e.g., Fosera).

Table 2. Mitigation strategies for behavioural challenges resulting from common electricity supply issues.

\begin{tabular}{|c|c|c|}
\hline Electricity Supply Challenge & Behavioural Challenge & Mitigation Strategies \\
\hline Blackouts & $\begin{array}{l}\text { eCooking not possible until power } \\
\text { returns }\end{array}$ & $\begin{array}{ll}\text { - } & \text { Insulated appliances [32] } \\
\text { - } & \text { Energy storage, e.g., batteries [4,5], thermal storage [42,43] } \\
\text { Fuel stacking [4] }\end{array}$ \\
\hline Brownouts (voltage dips) & eCooking slow & $\begin{array}{ll}- & \text { Voltage stabilisers [32] } \\
- & \text { Insulated appliances [32] } \\
\text { - } & \text { Cook at off-peak times [4,32] } \\
\text { Energy storage-batteries (CREST), phase change materials [42,43], } \\
\text { thermal storage (CREST) } \\
\text { - Fuel stacking [4] }\end{array}$ \\
\hline $\begin{array}{l}\text { Limited power available (e.g., limited } \\
\text { load connections) }\end{array}$ & $\begin{array}{l}\text { Conventional high-power eCooking } \\
\text { appliances cannot be used at all }\end{array}$ & $\begin{array}{ll}\text { - } & \text { Low power and insulated appliances }[32,36] \\
\text { - Fuel stacking [4] }\end{array}$ \\
\hline $\begin{array}{l}\text { Limited energy available (e.g., battery } \\
\text { storage) }\end{array}$ & $\begin{array}{l}\text { Conventional high-power eCooking } \\
\text { appliances cannot be used for very long }\end{array}$ & $\begin{array}{l}\text { - } \quad \text { Reduce electricity demand with energy-efficient appliances }[4,6,7] \\
\text { Fuel stacking [4] }\end{array}$ \\
\hline No grid access & eCooking not possible & $\begin{array}{ll}\text { - } & \text { SHS sized for cooking [31] (SunCulture and SCODE) } \\
\text { - } & \text { Direct-drive DC appliances }[25,42,44] \\
\text { Fuel stacking [4] }\end{array}$ \\
\hline High tariff & eCooking expensive & $\begin{array}{l}\text { - } \quad \text { Reduce electricity demand with energy-efficient appliances }[4,6,7] \\
\text { - } \quad \text { Fuel stacking [4] }\end{array}$ \\
\hline
\end{tabular}


The lack of reliable electricity supply and the coincidence of cooking times with peak demand for electricity has hindered the widespread adoption of eCooking in many countries $[17,18,36]$. In Zambia, seasonal load shedding frequently occurs when hydropower resources run low, forcing many people who have already adopted eCooking to revert to charcoal when blackouts strike [18]. In Myanmar, the grid is often heavily overloaded, placing severe restrictions on how people cook with electricity. Low voltage can affect cooking just as much as blackouts by slowing down cooking (halving the voltage leaves just a quarter of the power at $115 \mathrm{~V}$, a $1 \mathrm{~kW}$ hotplate rated at $230 \mathrm{~V}$ becomes a $250 \mathrm{~W}$ hotplate; extreme voltage fluctuations were observed in rural areas, at times sagging to below $20 \mathrm{~V}$ on a grid designed for $230 \mathrm{~V}$ ) [32]. Focus group participants reported getting up as early as 2 am to begin cooking before the voltage starts to sag as the grid is loaded up throughout the day [32]. Meanwhile, a pilot project with induction stoves in a remote Nepali village concluded that limited micro-hydropower plant capacity will be a significant obstacle for eCooking, as Nepali people typically cook at the same time as peak demand for electricity [45]. However, a similar project on a solar-hybrid mini-grid in Haiti found that eCooking was a useful tool for increasing utilisation of renewable energy, as their customers typically cooked during the daytime [31].

Energy storage can make cooking with electricity more reliable and enable access in off-grid areas with solar PV [4,16-18]. Battery-supported cooking devices can shift electricity demand away from peak times and allow users to cook during blackouts or brownouts, however they add significantly to the cost-therefore optimising energy and power demand with efficient appliances is critical [33]. Other cheaper energy storage technologies are being developed [42,43], however they still struggle to match the ability of LPG to cope with days of exceptionally high demand (e.g., cooking for visitors), making fuel stacking an attractive option $[19,29]$.

How much electricity is really needed to cook?

The question of 'how much' sits at the heart of changing perceptions about the real costs of cooking with electricity. Until recently, there was very little evidence on how much electricity is really needed to cook local foods across the Global South. Building on Cowan's [46] early work, MECS has adopted two distinct approaches:

1. Sets of CCTs and UCTs (Controlled and Uncontrolled Cooking Tests) have been designed to directly compare energy consumption for specific dishes across electric and nonelectric cooking devices. The results obtained to date from Uganda, Haiti, Kenya, Zambia and Tanzania show that most dishes can be cooked with just $0.1-0.6 \mathrm{kWh}$ in an energy-efficient appliance [6,7,31,32,39].

2. Cooking diary studies have recorded energy consumption in real kitchen environments [47]. Results to date from Myanmar, Kenya, Zambia, Haiti, Tanzania and Nepal indicate that cooking all your food with electricity uses just 1-2 kWh per household per day $[4,32,47]$.

\subsection{Household and Setting Characteristics}

\subsubsection{Changing Lifestyles}

"Cooking with electricity is easier, even men can do it".

MECS Cambodia Country Partner.

eCooking has been shown to offer a range of co-benefits for both genders, in particular, when cooking appliances with energy storage can also enable more reliable access to electricity $[4,5]$. Literature on the barriers to the adoption of modern energy for cooking often highlights traditional decision-making roles in the household as a major challenge, with women as the primary users of household cooking devices, but men often control household finances [48-50]. Nevertheless, energy-efficient appliances can make cooking easier, with several studies indicating that this may empower men to start taking an active role in the kitchen [51-53]. Additionally, battery-supported cooking devices can also enable access to other popular low-power energy services, such as mobile phone charging, TV and radio for households in off-grid and weak-grid contexts [4,5]. As a result, this is likely 
to make them an attractive investment for households who can repurpose their existing household expenditure on traditional cooking fuels for repayments of a financed eCooking device and/or electricity units. By appealing to both household decision-makers and cooks, eCooking may enable households to break out of the business-as-usual cycle in the clean cooking sector, with women needing cookstoves and men prioritising other things that they think are more important.

In all the countries analysed in this paper, the use of electricity for cooking does tend to correlate with higher household incomes, better financial connectivity, urbanisation, and other forms of 'modern' living $[4,54,55]$. In contrast, low-income households on the fringes of the economy often have firewood as the only affordable choice; for these households, other immediate needs take precedence over cooking with clean fuels, dwindling incomes and unplanned financial constraints (e.g., unexpected health expenses, loans) encourage stacking of biomass.

However, urbanisation is accelerating rapidly across SSA [3], and innovative consumer financing mechanisms for appliances (explored in Financial, Tax and Subsidies) are opening up eCooking to market segments beyond the elite. The most lucrative and immediately addressable market for eCooking is the households who already pay for charcoal and wood $[4,56]$. This market is expanding rapidly as increasing urbanisation is driving a transition for many households collecting firewood towards purchasing firewood, charcoal or other cooking fuels [57]. Marketing eCooking to households who are already paying for their cooking fuel is much easier, as repurposing their existing expenditures with electricity units and repayments on financed appliances is a more attractive proposition than convincing people to start paying for cooking. Moreover, as approximately half of the wood-buyers in SSA and SSEA are located in peri-urban/urban areas, they have greater access to electricity, compared to their rural counterparts [56]. The growing trend of rapid urbanisation among the youth presents an opportunity for understanding their behaviour and exploring whether their experiences with modern cooking can be harnessed as a force to influence families they have left in rural areas [56].

However, even amongst those who still collect their cooking fuel, eCooking could still be promoted without creating an additional financial burden on poorer households if paired with income-generating activities. Electric appliances can enable and enhance a range of productive uses of energy, which, if promoted alongside eCooking appliances, could allow households to generate additional income, which could support the costs of eCooking [4]. Cooking itself is, of course, also a productive use of energy, and eCooking could enable street vendors, restaurants and institutions to earn additional income [58].

\subsubsection{Fuel and Appliance Stacking}

By and large, users do not simply switch from one fuel or technology to another, but follow a multiple-use strategy, whereby new technologies and fuels are used without abandoning the previous ones [59]. This allows users to take advantage of both traditional and modern fuels and technologies by using each one for the task that it best performs and to increase energy security [60].

Stacking, as this is often called, is a phenomenon observed in all MECS countries, however patterns of stacking vary between countries [61]. For example, households in urban Zambia frequently stack charcoal with electricity to mitigate the effects of load shedding [18], whilst households in urban Kenya often stack charcoal with LPG to cook 'heavy foods' and 'light foods', respectively [19]. Understanding stacking involves considering the number of technologies in use, how often they are used, and the variation of these factors over time [61].

Energy-efficient electric cooking appliances are often highly task-specific. For example, a toaster is fantastic at toasting bread, but not much use for anything else. As a result, the likelihood that households will need to complement energy-efficient electric cooking appliances with other cooking devices is high. 
From a health perspective, eliminating stacking is not the aim, instead it is nudging households towards a clean fuel stack. Stacking clean and dirty fuels can potentially reduce Indoor Air Pollution (IAP), however the evidence shows that this is not a linear relationship, i.e., using $50 \%$ charcoal and $50 \%$ electricity does not result in $50 \%$ improved health outcomes [62]. However, as people get used to the convenience of modern fuels, they may choose to use them more often if circumstances allow it, especially if encouraged with well-targeted BCTs, such as training on cooking specific food types commonly cooked with biomass.

In urban East Africa, promoting EPCs amongst LPG users is a promising strategy for encouraging households to move completely away from biomass $[4,63]$. Charcoal stoves are often used for 'heavy foods' that require boiling for several hours, such as beans or matumbo (tripe), for which EPCs offer the greatest energy and time savings [6]. Whilst these findings have been extended to other contexts where 'heavy foods' also form a major part of local menus (e.g., Tanzania, Zambia, Uganda [7,31,39]), EPCs offer fewer advantages in contexts where foods are typically cooked for shorter durations, or where other cooking processes (e.g., baking, deep frying) are more widely used. In these contexts, there is a need to follow a similar research journey, of firstly understanding what is cooked and how, then matching the dominant cooking processes with appliances optimised for them.

Electric appliances can also be stacked and an appliance stack is much more likely to enable the exclusive use of electricity for cooking than a single appliance alone $[4,31]$. Households in Myanmar that exclusively use electricity for cooking frequently own a kettle for water boiling, a rice cooker for rice and soup and an electric frying pan for curries [17]. Understanding the appliance stacks that fits best with each cooking culture is an important step on the eCooking research journey. The relative strengths/weaknesses of specific electric appliances can cause households to change their menu, in Tanzania, a shift from ugali to rice and beans was observed among firewood/charcoal users testing EPCs [64,65], and in Nepal, chapati to dal-rice meals among firewood users trialling induction stoves [36]. It is important to note that exclusive use of electricity for cooking requires a reliable supply of electricity [54], however, this can be mitigated by energy storage [4].

\subsection{Knowledge and Perceptions}

Perception of cost-electricity is 'too expensive for cooking'.

In many developing countries, there is a widespread perception that electricity is 'too expensive for cooking'. This is evidenced by engagements with clean cooking and electrification sector stakeholders, household surveys and focus groups [16-18]. However, the evidence presented below (see Financial, Tax and Subsidy) shows that this is not necessarily the case, as electricity is often actually cheaper than other cooking fuels. Cooking diary studies in Tanzania and Kenya [19,29], where electricity tariffs are moderate (compared to typical SSA rates [4]) found that although participants initially perceived eCooking to be expensive, the majority actually saved money when switching to electricity. This widespread perception of electricity as expensive often results in a very conservative attitude towards the use of electricity, only using it when absolutely essential for fear of incurring high bills [66].

The evidence shows that just because people are using electricity for other purposes, it is not sufficient to shift mindsets towards eCooking [3,4] — people need to see for themselves just how little electricity is required to cook with energy-efficient appliances. Electricity is usually metered for households as a whole rather than individual appliances. As a result, it is often difficult for households to know how much electricity is being consumed by each appliance, in particular by the electric cooking appliances, which many people assume with be very energy-intensive. Findings in Cambodia, Tanzania and Kenya indicate that plug-in energy meters can offer a powerful behavioural nudge that could encourage households to adopt eCooking simply by making the invisible visible to give the cook control over their electricity consumption $[19,30,41,56]$. 


\subsubsection{Safety}

There are mixed perceptions regarding the safety of eCooking. Evidence from Myanmar [32] revealed a perception of eCooking appliances as unsafe, due to the risk of shocks, and evidence from Kenya shows similar perceptions around the safety of pressure cooking due to the risk of explosions [6]. Both perceptions are likely, due to the abundance of poor-quality devices, which have caused serious injuries. Poor quality wiring is also a safety concern, especially for low-income households, as eCooking appliances can easily overload thin cables designed for lighting [35].

The adoption of EPCs, in particular, is held back by these negative perceptions. EPCs incorporate an array of control and safety mechanisms to regulate their internal pressure and prevent the lid from opening whilst pressurised to avoid the accidents that commonly occur with stove-top pressure cookers [39]. However, few consumers are aware of the enhanced safety features of EPCs and simply perceive them to be equally as dangerous as stove-top pressure cookers. Conversely, after trialling EPCs for a month at home, participants in a cooking diaries study in Kenya rated EPCs as safer than hotplates [19]. Interestingly, there was not a single safety concern with the rice cookers also tested by participants, which are also insulated, but unpressurised. Insulation not only improves efficiency, but can also safeguard cooks and their children from burns [39].

\subsubsection{Taste}

Whilst the conventional discourse points to the lack of smoky flavour and other elements of taste and texture that are only achievable with biomass cooking as insurmountable barriers for eCooking, recent studies have shown that the reality is more nuanced. Taste is highly subjective and perceptions vary with the cultural environment. Traditional forms of cooking may, therefore, be associated with better taste simply because they are connected to other cultural traditions. However, the opposite can also be true, with those aspiring to a modern lifestyle that breaks free from these traditions potentially wanting to disassociate themselves from the smoky flavour typical of foods cooked with biomass. The evidence shows that smoky flavours are indeed preferred by some people for some specific foods, however, others prefer food without the smoky flavour (see Figure 1) [19,67]. Food cooked with electricity was rated as the tastiest overall by cooking diary participants in Kenya and during blind taste tests in Myanmar [19,68]. However, some foods are more difficult to cook with electric appliances than others. Flatbreads, such as chapati, are difficult to cook with an electric hotplate or an induction stove, which tend to focus their heat in specific areas rather than heating evenly like charcoal. This explains why Kenya cooking diary participants rated chapati as the least tasty dish when cooked with electricity [19], a finding that was also observed with induction stove users in Nepal [45].

\section{Do you miss the smokey flavour of food? If so, for which dishes in particular?}

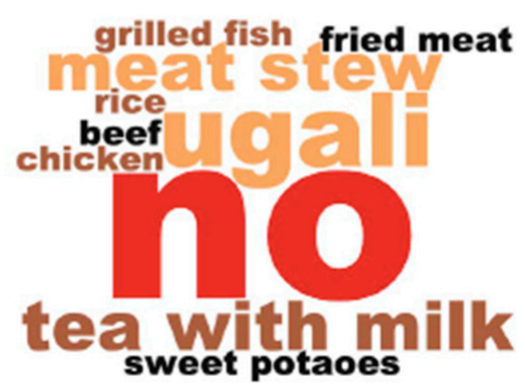

Figure 1. Word cloud summarising opinions of cooking diary participants in Kenya after testing eCooking appliances at home for a month [19]. 


\subsection{Financial, Tax and Subsidy}

Actual relative cost-is electricity really 'too expensive for cooking'?

The previous section drew attention to the common perception that electricity is 'too expensive for cooking', whilst this section seeks to explore the conditions under which this perception is true or not. It is true that some countries have relatively high electricity tariffs and that some appliances are very inefficient; under such conditions, using electricity will almost certainly be more expensive than other cooking fuels [4]. It is also true that in many rural areas, households are collecting fuel for free, meaning that no matter what the cost, electricity will always be more expensive unless it is 100\% subsidised.

Evidence from eight MECS countries $[4,31,45,52,69]$ shows that eCooking and electricity tariffs have an inverse relationship, i.e., people cook more with electricity when the tariff is low, suggesting that cost is one of the key barriers to the adoption of eCooking. What is more, there is a clear relation between the adoption of electricity for cooking and higher incomes [18,52]. This is supported by evidence from an EPC solar-hybrid mini-grid trial in Tanzania, which found that the use of eCooking shot up dramatically when the tariff was reduced by order of magnitude (from over $1 \mathrm{USD} / \mathrm{kWh}$ to $0.04 \mathrm{USD} / \mathrm{kWh}$ ) [64].

"People love cooking with electricity, but not paying for it".

A2EI, Tanzania [64].

ESMAP [4] drew attention to the fact that there are a growing number of contexts where cooking with energy-efficient electric appliances is on a par with, or in some cases cheaper than other popular cooking fuels. In particular, urban centres, where the price of charcoal is highest, and grid electricity is most widely available and most reliable. ESMAP's data shows that charcoal is increasingly becoming more expensive, while electricity is growing more affordable, in particular, in weak- and off-grid contexts where energy storage is required. They highlight that eCooking on national grids, or micro-hydropower is already cost-effective for many people today, and that eCooking on solar-hybrid mini-grids and battery-supported DC eCooking are likely to become cost-effective by 2025. The findings also showed that using a clean fuel stack of LPG and a highly efficient eCooking appliance is often the most cost-effective way to cook and that clean fuel stacks can make these emerging eCooking technologies cost-effective today.

\subsubsection{Consumer Finance Mechanisms}

Even amongst the increasing number of households for whom the cost of electricity units for cooking are on a par with, or below, current expenditures on cooking fuels, the upfront cost of electric appliances, in particular, energy-efficient appliances, is usually substantially higher than ICS and comparable to LPG stove/cylinder combinations. As a result, this presents a substantial barrier for many, as even those who can afford to pay this amount may not be willing to until they are convinced that it will really add value to their kitchen.

Consumer finance mechanisms have a critical role to play in overcoming one of the most challenging hurdles for low- and even middle-income households by breaking down the high upfront cost into affordable repayments. ESMAP note that "the uptake of eCooking will depend substantially on the willingness of energy service companies to integrate it into the suite of services they offer. For example, utilities with excess generating capacity could stimulate demand by developing an on-bill financing mechanism for EPCs and support women entrepreneurs to leverage their social networks to demonstrate new cooking technologies and practices" [4]. However, there are many different forms that they can take, but some of the most promising include:

- Microfinance, such as revolving funds, which allow groups to pool their savings and buy for each member in turn. This model can leverage pre-existing savings groups and simultaneously address other challenges by providing channels for live cooking demonstrations and after-sales support [40,41].

- Utility enabled finance, such as on-bill financing, can reduce the behavioural change required to make repayments for consumers already paying an electricity bill. Util- 
ities have a unique relationship with low-income customers, with insight into their cash-flow, and can adapt their services accordingly [70]. However, developing these mechanisms requires substantial groundwork to establish the business case to convince executives within the utility to pilot and then scale up the initiative.

- Pay-As-You-Go (PAYG), or in the context of eCooking, Pay-As-You-Cook (PAYC) offers appliance manufacturers and distributors the ability to sell products to any customer [52]. Whilst other cooking technologies have struggled with this model, integrating energy metering and/or a locking mechanism into electric appliances is much easier than for other cooking devices.

\subsubsection{Subsidies}

Subsidies can be effective mechanisms for facilitating the uptake of eCooking, if they are well-targeted. ESMAP note that "markets that feature substantial, long-standing fuel subsidies and national support programmes that impact end-user prices (e.g., electricity in Myanmar and LPG in Cambodia and Nepal) allow for more widespread adoption of primary clean fuels" [48]. Access to these subsidies could increase the adoption of eCooking, however, they must be carefully designed to reach the most vulnerable without increasing inequality [71,72]. South Africa is the only Sub-Saharan African nation where the majority of the population cook with electricity [73] through a means-tested Free Basic Electricity (FBE) programme introduced in some municipalities to enable low-income households to use electricity for cooking by offering $50 \mathrm{kWh} /$ month free of charge [74]. However, uptake of eCooking amongst low-income households has not been as significant as hoped and has even pushed some households further into poverty when they reportedly started cooking with electricity thinking it was cheap and accidentally exceeded this allowance, ending up with bills that they were unable to pay [75]. This highlights the need to enable consumers to track their expenditures as they are cooking. Gould's [66] analysis showed that the Ecuadorian government's programme to reduce national expenditure on LPG subsidies by facilitating the uptake of eCooking was less successful, as LPG is still the primary cooking fuel for most households. $80 \mathrm{kWh} /$ month was offered for free to participating households, along with an on-bill financing option for the appliance. However, many chose to continue using LPG (which was still subsidised) and use the free electricity for watching TV.

\subsubsection{Lifeline Tariffs}

Many countries already offer lifeline tariffs that are generous enough for cooking, however the problem of shared meters prevents many low-income households from benefiting [52,57]. Zambia offers a very generous lifeline tariff $(0.015 \mathrm{USD} / \mathrm{kWh}$ for the first $200 \mathrm{kWh} /$ month) [18], which the evidence from the cooking diaries shows is several times what most households need for cooking (30-60 kWh/month) [4]. However, many lowincome households share a meter with their landlords, meaning that the lifeline allowance may only benefit the landlord, who then charges a fixed rate to their tenants. In Zambia, landlords often specifically prohibit their tenants from cooking beans with electricity, as they know this is a very energy-intensive dish when cooked on a hotplate [57]. Researchers in Cambodia observed similar challenges:

"My landlady often asks me to stop because we share a meter. Like most people, she assumes that cooking with electricity is very expensive and I can't prove to her how much I'm using"-Cambodian interview participant [52].

\subsection{Market Development}

\subsubsection{Stimulating Demand}

The market for eCooking technologies is nascent in much of the Global South, however a suite of targeted efforts is underway from both conventional appliance distributors, and more recently, energy service providers utilising eCooking appliances to stimulate demand for electricity itself [4,76]. Studies in Tanzania [77], Cambodia [52], Kenya [40] found that awareness campaigns featuring cooking demonstrations with local foods designed to 
increase knowledge and change the attitudes and perceptions of everyday cooks toward eCooking were effective in stimulating demand for eCooking. Specifically, these campaigns focused on changing perceptions of pressure cooking (from dangerous to safe), eCooking appliances (from complicated to convenient), taste (from unfamiliar or inferior to delicious) and of the cost of eCooking, from expensive to affordable. Live cooking demonstrations give potential customers the opportunity to experience the speed, convenience, energyefficiency and cost savings of eCooking by seeing, smelling and tasting for themselves. Demonstrations can effectively convey the ease with which new devices, such as EPCs, can cook local dishes and offer potential users the ability to ask questions about safety, financial support, distribution points and other concerns.

Additionally, word of mouth (communication between consumers) is often effective because the sources view the information as credible and without commercial influence [78]. Leveraging social networks, both physical and virtual, have proven to be powerful tools in getting people excited about eCooking, whilst simultaneously enabling both sales and after-sales support from a trusted entity $[40,41]$.

\subsubsection{Supply Chain and after Sales Service}

Facilitating the adoption and sustained use of any new technology requires the presence of an effective supply chain. Currently, the supply chain for eCooking appliances is very weak in many parts of SSA, with the notable exception of South Africa, where eCooking is already widely adopted, and appliance manufacturing is already well established [18]. In Tanzania [77], findings emphasised the criticality of a local supply chain and linking manufacturers to supermarkets, distributors and rural end users. The first Results Based Financing (RBF) exclusively for eCooking in SSA has just concluded in Kenya, to develop the supply chain by incentivising appliance distributors to purchase a total of 5000 EPCs in bulk [79].

Although the eCooking supply chain is much stronger in SSEA, in particular, India, where substantial volumes of eCooking appliances are manufactured both for the domestic and export markets, challenges still remain in remote areas. A study on microhydro minigrids in Nepal [36] was hindered by the lack of high quality energy-efficient appliances and battery storge on the local market, resulting in the need to import from India, adding cost and delays. In Cambodia [52], the lack of well-paved roads posed a challenge to the supply of electric devices to rural regions, highlighting the need for better infrastructure to support last-mile distribution.

After-sales support is critical for customer satisfaction and retention [48]. A pilot project in Kenya [40] found that many importers did not stock parts and had little interest in doing so. For example, participants frequently requested an additional inner pot for EPCs, as the non-stick coating has a limited life, and an additional pot can make cooking multiple dishes more convenient. As EPCs can only function with the specific pot they were shipped with, the appliance is effectively rendered obsolete if a spare cannot be obtained. Similarly, a study in Cambodia [52] found that customers want guarantees that the appliances they buy are durable.

ESMAP [4] note that developing a new supply chain from scratch is challenging, nevertheless, eCooking offers a unique opportunity to leverage the existing supply chains of electricity service providers, such as utilities (e.g., KPLC), mini-grid developers (e.g., PowerHive, PowerGen, PowerCorner) and SHS distributors (e.g., MKopa, SCODE, SunCulture) (see Figure 2). These electricity service providers have already established strong relationships with their customers and developed supply chains for importing, distributing, storage and servicing hardware. For these organisations, their primary commercial activity is the supply of electricity, however to stimulate demand for electricity units, many have begun to branch out into selling appliances. More recently, this has begun to include eCooking appliances. Importantly, these electricity suppliers are more likely to sell qualityassured appliances and offer after-sales support, as they have the motivation to ensure ongoing sales of electricity units. 


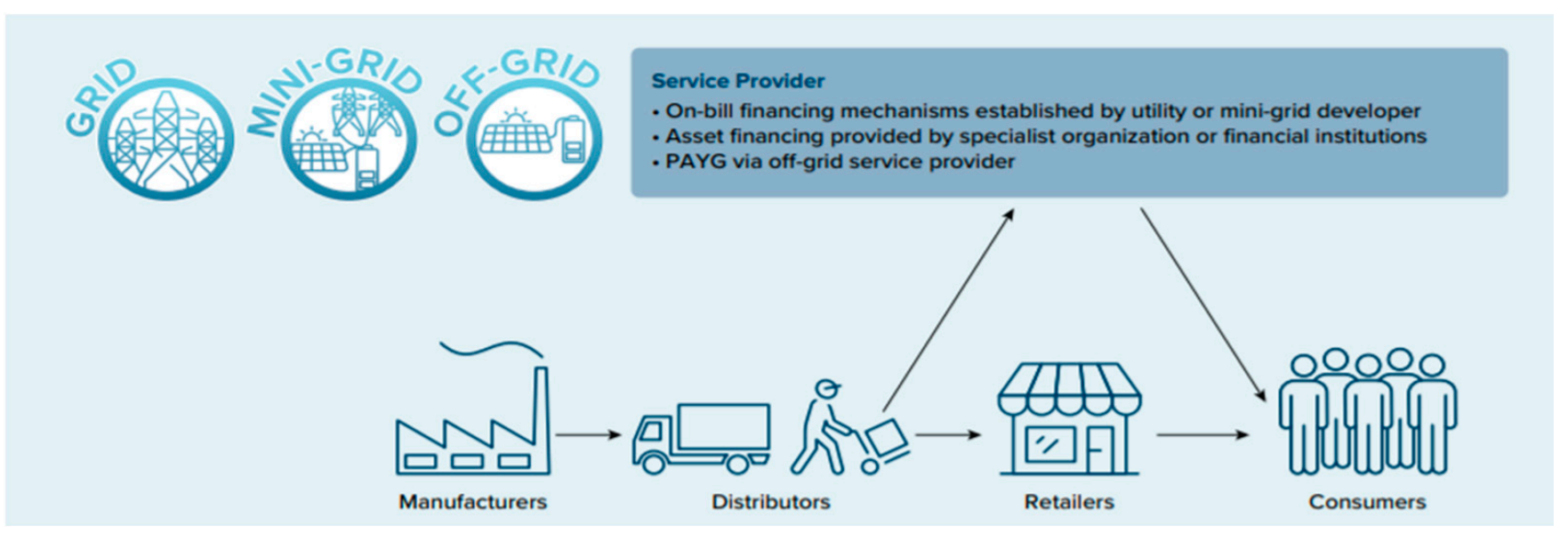

Figure 2. New opportunities to leverage the existing supply chains of electricity service providers. Source: Adapted from work by the authors of [4].

\subsection{Regulation, Legislation and Standards}

Quality appliances are critical to the sustainability of an eCooking transition in developing countries. Effective Quality Assurance (QA) regimes can ensure that only the most durable appliances make it into the market [80]. Developing effective standards, testing procedures and test labs are a critical part of that process. The Global LEAP Awards takes a competition-based approach to QA by incentivising appliance manufacturers to design energy-efficient, durable, safe affordable and user-friendly appliances. In 2020, the Global LEAP Awards launched its first eCooking competition to identify the best-in-class EPCs through a combination of rigorous laboratory testing and usability testing with everyday cooks in Nairobi [39]. Many of the EPCs entered the competition did not meet the minimum performance standards required to achieve finalist status in the competition and appear in the Buyers' Guides designed to inform distributors intending to purchase in bulk. In particular, regarding safety concerns, highlighting the need for effective QA mechanisms to protect consumers from poor quality dangerous appliances. The Global LEAP offers a blueprint to develop national testing programmes, consumer labelling and Minimum Energy Performance Standards (MEPS) for eCooking. Developing robust standards, legislation and testing for eCooking appliances could help prevent poor quality products from entering the market and contributing to this growing problem.

Consumers are key stakeholders in ensuring the rejection of sub-standard goods by opting for high quality, energy-efficient ones. Although, there is increasing evidence that consumers rarely consider energy-efficiency when purchasing household appliances [81]. Reasons for this include lack of knowledge on energy consumption and how it corresponds to ongoing costs; unfamiliarity with the format information provided; limited attention and perception biases; uncertainty bias; social networks and norms, and household liquidity constraints [82,83]. Findings from the usability testing for the 2020 EPC Global LEAP in Kenya show that despite its direct relationship to running costs, efficiency was not prioritised compared to other attributes, such as safety, functionality, durability, cooking capacity, ease of use and appearance [39]. Consumer labelling clearly showing the differences between the running costs of each appliance could support users to make better decisions, which will also signal to manufacturers that designing efficient appliances is important.

\section{Discussion}

This section presents some of the innovative marketing strategies that MECS partners have explored to overcome the barriers identified in the previous sections and to amplify the drivers (summarised in Table 3). It draws upon the BCTs and theoretical frameworks presented at the beginning of the paper (see Appendix A for further detail), to analyse what 
has already been done and inform the development of future programmatic and policy mechanisms designed to facilitate the uptake of eCooking.

Table 3. Summary of innovative marketing strategies developed by MECS partners to overcome behavioural change challenges and leverage the drivers. See Appendix A for further detail on BCT classifications [24].

\begin{tabular}{|c|c|c|c|c|}
\hline $\begin{array}{l}\text { Behavioural Change } \\
\text { Barrier/Driver }\end{array}$ & Marketing Strategies & $\begin{array}{l}\text { BCT Classification } \\
\text { [24] }\end{array}$ & $\begin{array}{l}\text { Ongoing MECS } \\
\text { Research/Piloting }\end{array}$ & Future Areas of Investigation \\
\hline $\begin{array}{l}\text { Positioning eCooking as } \\
\text { an aspirational cooking } \\
\text { experience }\end{array}$ & $\begin{array}{l}\text { Connecting with local } \\
\text { food bloggers and other } \\
\text { popular media icons. } \\
\text { Emphasising convenience } \\
\text { and cost savings. }\end{array}$ & $\begin{array}{l}\text { Goals, planning and } \\
\text { monitoring, identity } \\
\text { and self-belief, } \\
\text { shaping knowledge }\end{array}$ & $\begin{array}{c}\text { Jikoni Magic, Mediae, } \\
\text { Culinary WorkStream } \\
\text { (WS) }\end{array}$ & $\begin{array}{l}\text { Expanding reach by connecting } \\
\text { with a broader range of influencers } \\
\text { in Kenya and extending to other } \\
\text { countries. Refine messaging to } \\
\text { reflect what is most important to } \\
\text { cooks in each context }\end{array}$ \\
\hline $\begin{array}{l}\text { Male decision-makers not } \\
\text { authorising purchases }\end{array}$ & $\begin{array}{l}\text { Marketing campaigns, } \\
\text { including men as } \\
\text { decision-makers }\end{array}$ & $\begin{array}{l}\text { Identity and } \\
\text { self-belief, shaping } \\
\text { knowledge }\end{array}$ & Mediae & $\begin{array}{l}\text { Marketing campaigns targeting } \\
\text { men as cooks }\end{array}$ \\
\hline $\begin{array}{l}\text { Diversity in individual } \\
\text { preferences, motivations } \\
\text { and aspirations }\end{array}$ & $\begin{array}{l}\text { Building a set of personas } \\
\text { to represent key consumer } \\
\text { groups and developing } \\
\text { customised strategies for } \\
\text { each. }\end{array}$ & $\begin{array}{l}\text { Goals, planning and } \\
\text { monitoring, identity } \\
\text { and self-belief }\end{array}$ & $\begin{array}{l}\text { Burn, MKopa, } \\
\text { SD4MECS (Service } \\
\text { Design for MECS) }\end{array}$ & $\begin{array}{l}\text { Development of a modular } \\
\text { persona toolkit }\end{array}$ \\
\hline \multirow{4}{*}{$\begin{array}{l}\text { False perception of high } \\
\text { ongoing costs }\end{array}$} & $\begin{array}{l}\text { Energy meters sold with } \\
\text { appliances }\end{array}$ & Shaping knowledge & iDE, Jikoni Magic & $\begin{array}{l}\text { Interoperable technology to } \\
\text { integrate energy metering into any } \\
\text { eCooking appliance }\end{array}$ \\
\hline & $\begin{array}{l}\text { Free electricity units } \\
\text { during the trial period }\end{array}$ & $\begin{array}{l}\text { Reward and threat, } \\
\text { shaping knowledge }\end{array}$ & EarthSpark & $\begin{array}{l}\text { Developing scalable package for } \\
\text { new customers, with feedback on } \\
\text { actual consumption }\end{array}$ \\
\hline & $\begin{array}{l}\text { Live cooking demos with } \\
\text { energy metering }\end{array}$ & $\begin{array}{l}\text { Shaping knowledge, } \\
\text { Comparisons }\end{array}$ & $\begin{array}{l}\text { KPLC, iDE, Jikoni } \\
\text { Magic, TaTEDO }\end{array}$ & $\begin{array}{l}\text { Empowering sales agents in } \\
\text { peer-to-peer marketing to replicate } \\
\text { metered demonstrations }\end{array}$ \\
\hline & $\begin{array}{l}\text { eRecipes and eCookBooks } \\
\text { to compare } \\
\text { fuels/appliances }\end{array}$ & $\begin{array}{l}\text { Shaping knowledge, } \\
\text { Comparisons }\end{array}$ & $\begin{array}{l}\text { Culinary WS, Hivos, } \\
\text { CEEEZ, Finovista, } \\
\text { KPLC, ACTS, CREEC }\end{array}$ & $\begin{array}{l}\text { Produce eRecipes and eCookBooks } \\
\text { for a broader range of cuisines and } \\
\text { appliances. Expanding the range } \\
\text { of more digestible content, e.g., } \\
\text { YouTube videos, Instagram stories. }\end{array}$ \\
\hline $\begin{array}{l}\text { High ongoing costs (e.g., } \\
\text { solar mini-grids) }\end{array}$ & Discounted cooking tariffs & $\begin{array}{l}\text { Reward and threat, } \\
\text { Regulation }\end{array}$ & $\begin{array}{l}\text { A2EI, PowerGen, } \\
\text { EarthSpark }\end{array}$ & Appliance-level metering \\
\hline \multirow[t]{2}{*}{$\begin{array}{l}\text { Safety and perception of } \\
\text { safety }\end{array}$} & $\begin{array}{l}\text { Live cooking demos } \\
\text { focussing on safety }\end{array}$ & Shaping knowledge & $\begin{array}{l}\text { KPLC, iDE, Jikoni } \\
\text { Magic }\end{array}$ & $\begin{array}{l}\text { Broader awareness-raising } \\
\text { campaigns }\end{array}$ \\
\hline & Quality standards & Regulation & Strathmore, CLASP & $\begin{array}{l}\text { National standards to exclude } \\
\text { unsafe appliances }\end{array}$ \\
\hline \multirow[b]{2}{*}{$\begin{array}{l}\text { Perception that food will } \\
\text { not taste as good }\end{array}$} & $\begin{array}{l}\text { Live cooking demos with } \\
\text { tasting }\end{array}$ & $\begin{array}{l}\text { Shaping knowledge, } \\
\text { Comparisons }\end{array}$ & $\begin{array}{l}\text { KPLC, iDE, Jikoni } \\
\text { Magic, SESCOM }\end{array}$ & $\begin{array}{l}\text { Trial periods with no obligation to } \\
\text { purchase }\end{array}$ \\
\hline & $\begin{array}{l}\text { eRecipes and eCookBooks } \\
\text { showcase which } \\
\text { appliances fit best with } \\
\text { local cuisine and share } \\
\text { cooking tips for local } \\
\text { foods }\end{array}$ & $\begin{array}{l}\text { Shaping knowledge, } \\
\text { Comparisons }\end{array}$ & $\begin{array}{l}\text { Culinary WS, Hivos, } \\
\text { CEEEZ, Finovista, }\end{array}$ & $\begin{array}{l}\text { Produce eRecipes and eCookBooks } \\
\text { for a broader range of cuisines and } \\
\text { appliances. Expand range of more } \\
\text { digestible content, e.g., YouTube } \\
\text { videos, Instagram stories. }\end{array}$ \\
\hline \multirow{3}{*}{$\begin{array}{l}\text { Learning curve for new } \\
\text { appliances }\end{array}$} & $\begin{array}{l}\text { Packaging, manuals and } \\
\text { interface adapted to the } \\
\text { local cooking culture }\end{array}$ & Shaping knowledge & iDE, SESCOM, CLASP & $\begin{array}{l}\text { Local distributors in each country } \\
\text { adapt packaging, manuals and } \\
\text { interface to their cooking culture }\end{array}$ \\
\hline & Live cooking demos & $\begin{array}{l}\text { Shaping knowledge, } \\
\text { Comparisons }\end{array}$ & $\begin{array}{l}\text { KPLC, iDE, Jikoni } \\
\text { Magic }\end{array}$ & $\begin{array}{l}\text { Trial periods with no obligation to } \\
\text { purchase }\end{array}$ \\
\hline & Peer-to-peer marketing & Social support & $\begin{array}{l}\text { Jikoni Magic, Bidhaa } \\
\text { Sasa }\end{array}$ & $\begin{array}{l}\text { Creating a feedback loop from } \\
\text { sales agents to manufacturers }\end{array}$ \\
\hline
\end{tabular}


Table 3. Cont.

\begin{tabular}{|c|c|c|c|c|}
\hline $\begin{array}{l}\text { Behavioural Change } \\
\text { Barrier/Driver }\end{array}$ & Marketing Strategies & $\begin{array}{l}\text { BCT Classification } \\
\text { [24] }\end{array}$ & $\begin{array}{l}\text { Ongoing MECS } \\
\text { Research/Piloting }\end{array}$ & Future Areas of Investigation \\
\hline \multirow{4}{*}{$\begin{array}{l}\text { High upfront cost of } \\
\text { appliances }\end{array}$} & PAYC & Reward and threat & iDE, MKopa, SCODE & Interoperable PAYC technology \\
\hline & $\begin{array}{l}\text { Utility-enabled financing } \\
\text { (on-bill financing, on-bill } \\
\text { repayments, etc.) }\end{array}$ & $\begin{array}{l}\text { Changing the physical } \\
\text { environment }\end{array}$ & EnerGrow & $\begin{array}{l}\text { Scoping studies for specific utilities } \\
\text { Brokering partnerships between } \\
\text { utilities and asset financers }\end{array}$ \\
\hline & Revolving funds & Social support & $\begin{array}{l}\text { Jikoni Magic, Bidhaa } \\
\text { Sasa }\end{array}$ & $\begin{array}{c}\text { Brokering partnerships with } \\
\text { appliance distributors and savings } \\
\text { groups }\end{array}$ \\
\hline & Tax exemptions & Regulation & CLASP & $\begin{array}{l}\text { Linking tax exemptions with } \\
\text { quality standards and consumer } \\
\text { labelling to showcase high quality } \\
\text { energy-efficient appliances }\end{array}$ \\
\hline \multirow{3}{*}{ Fuel stacking } & $\begin{array}{l}\text { Promote appliance stacks } \\
\text { that are well matched to } \\
\text { local cuisine }\end{array}$ & $\begin{array}{l}\text { Comparisons, shaping } \\
\text { knowledge }\end{array}$ & EarthSpark, KPLC & $\begin{array}{l}\text { Map out the menu in different } \\
\text { countries/regions and match with } \\
\text { appliances designed for dominant } \\
\text { cooking practices. Household } \\
\text { trials of different appliance stacks. }\end{array}$ \\
\hline & Promote clean fuel stacks & $\begin{array}{l}\text { Comparisons, shaping } \\
\text { knowledge }\end{array}$ & SCODE & $\begin{array}{l}\text { Brokering partnerships between } \\
\text { LPG, appliance and electricity } \\
\text { distributors }\end{array}$ \\
\hline & $\begin{array}{l}\text { Targeted nudges to } \\
\text { eliminate biomass use }\end{array}$ & Reward and threat & UCL & $\begin{array}{l}\text { Identify key drivers of continued } \\
\text { biomass use and design targeted } \\
\text { BCTs }\end{array}$ \\
\hline \multirow{3}{*}{$\begin{array}{l}\text { Lack of } \\
\text { awareness/availability/ } \\
\text { after-sales service for } \\
\text { energy-efficient appliances }\end{array}$} & Peer-to-peer marketing & Social support & $\begin{array}{l}\text { Jikoni Magic, Bidhaa } \\
\text { Sasa }\end{array}$ & $\begin{array}{l}\text { Training programmes for sales } \\
\text { agents on appliance repair }\end{array}$ \\
\hline & $\begin{array}{l}\text { Electricity distributors } \\
\text { supplying and supporting } \\
\text { appliances }\end{array}$ & $\begin{array}{l}\text { Changing the physical } \\
\text { environment }\end{array}$ & $\begin{array}{l}\text { PowerGen, KPLC, } \\
\text { RVE.Sol, PowerHive, } \\
\text { PowerCorner }\end{array}$ & $\begin{array}{l}\text { Brokering partnerships between } \\
\text { electricity and appliance } \\
\text { distributors Training programmes } \\
\text { for electricity distributors on } \\
\text { appliance repair }\end{array}$ \\
\hline & $\begin{array}{l}\text { RBF programmes to } \\
\text { incentivise supply chain } \\
\text { development }\end{array}$ & $\begin{array}{l}\text { Changing the physical } \\
\text { environment }\end{array}$ & $\begin{array}{l}\text { CLASP/EnDev, Open } \\
\text { Capital/BGFA, } \\
\text { Scale-up WS }\end{array}$ & $\begin{array}{l}\text { Incorporation of eCooking into a } \\
\text { range of both clean cooking and } \\
\text { electrification RBF schemes } \\
\text { RBF programmes that incentivise } \\
\text { the sustained and exclusive use of } \\
\text { eCooking }\end{array}$ \\
\hline
\end{tabular}

\subsection{Behaviour Change Techniques (BCTs)}

Michie et al. [23] highlight the need to fully understand both the internal and external factors that influence household decision making to plan effective behavioural change interventions. Internal factors include capability, opportunities and motivation, whilst external factors include education, training, incentives, policies and regulations. The multiplicity of factors suggests a multifaceted approach, coupled with a detailed assessment of the prevailing or overriding factor in each context.

Table 3 shows that a broad range of BCTs is already being employed by MECS partners to facilitate the uptake and sustained use of eCooking. Evidently, shaping knowledge, providing incentives (reward and threat), comparisons, and social support have been the main techniques deployed to date. Although some efforts are ongoing in terms of regulations (e.g., dedicated cooking tariffs) and changing the physical environment (e.g., supply chain development and appliance financing), these types of BCTs could be deployed more frequently to create the enabling environment that could facilitate the scale-up adoption of eCooking.

\subsection{Is eCooking the Right Option, and If So, in What Form?}

In contexts where the adoption of electric cooking appliances is low, many consumers do not consider electricity as a viable option for cooking. In such situations, first and 
foremost, there is a need to establish which electric appliances can cook local foods and then find out how much electricity is required to do so. With this information, the relative costs, both upfront and ongoing, can also be compared to determine whether electric cooking is, or could soon become, an economically viable option in this context. If it can, then a series of BCTs can be designed to facilitate the uptake of eCooking (see Table 3). If it cannot, an exploration of enabling policies like a targeted subsidy, tax exceptions should be proposed.

\subsection{Is Seeing Believing? Tackling Perceptions of Cost, Taste and Safety with Immersive eCooking Experiences}

People often say that 'seeing is believing', however when it comes to cooking, seeing is just the first step towards convincing people. When it comes to food, smelling and tasting are equally important, but truly believing often only comes after consumers have tried the new cooking device for themselves and seen, smelled and tasted the food they have cooked. Targeted campaigns on TV, radio or social media generally fall into the first (1-awareness) of the five processes of adoption in Roger's Diffusion of Innovations Framework [20]. These can be complemented by further sources of information, such as live cooking demonstrations (2-persuasion). This may be enough to encourage the innovators to purchase an appliance (3-decision) to try it out themselves at home (4-trial). However, for others further down the diffusion curve with less appetite for risk and lower financial liquidity, this simply is not enough. Trial periods with limited financial risk to the consumer could enable them to experience the innovation by taking the appliances home and testing them out as part of their everyday kitchen routines (4-trial). If this experience is successful, then adoption will hopefully follow (5-confirmation). However, this presents a challenge for retailers, as offering this kind of immersive experience to every customer is not easy to accomplish cost-effectively. Applying behaviour change theory could increase the chances of adoption by enabling their potential customers to dive deeper into the experience of eCooking and increase the likelihood of sustained use by understanding how to support customers throughout their eCooking journey. Two examples are given below of MECS partners who have begun to explore this space.

Kenya Power, relaunched its Pika na Power (Cook with Electricity) campaign in 2017 to encourage its seven million customers to cook with electricity as a means to stimulate demand for surplus power on the national grid [20]. The campaign began as a TV show with local celebrity chefs and social media influencers cooking popular dishes with energyefficient electric cooking appliances. This was complemented by a series of YouTube recipes, a Facebook page and the establishment of a modern demonstration kitchen in central Nairobi. Members of the general public can attend live cooking classes twice a week, taste the food and buy the appliances they see being demonstrated directly afterwards. Of course, many consumers may see this as a ploy to increase their bills, so Pika na Power use plug-in energy meters to measure exactly how much electricity has been consumed as they cook each dish so that they can show the audience how much it really costs. Kenya has a diverse range of cultures, with many different languages and cuisines, so Pika na Power plans to extend this model to other regions of the country by setting up similar demonstrations and retail centres at their county showrooms. The BCT analysis in Table 3 highlights the fact that the network will also need to offer after-sales service to ensure their customers keep buying additional electricity units for eCooking in the long term. The Diffusion of Innovations suggests that they could also increase the likelihood of adoption by enabling attendees of their cooking classes to test out the appliances at home with minimal financial risk by offering a free trial period. This could be achieved by reimbursing any additional electricity units purchased and enabling customers to return any appliance they are not satisfied with during the first month after acquiring the new appliance.

In Cambodia, iDE's Facebook marketing platform aims to connect eCooking to current trends and position it as an aspirational cooking solution for modern Cambodians. iDE used Roger's framework [52] to create a set of personas for consumers at different stages of the diffusion curve. Their market research also found that the most effective messages for 
energy-efficient electric appliances were cost-savings and convenience. This contrasts with the health, environmental and gender equity messaging that often drive clean cooking programmes, such as MECS. To many everyday cooks, these issues simply are as important as the more immediate and tangible benefits of money and time savings. Consequently, iDE addressed the issue by selling appliances paired with energy meters so that customers can track how much they're really spending to cook with their new electric appliances. However, many potential customers are discouraged from purchasing, as they perceive that using these new appliances would be difficult. Applying the Theory of Planned Behaviour (TPB) [21] could help increase sales by designing targeted interventions to increase perceived behavioural control, e.g., demonstrations showcasing automatic controls that can actually make cooking much easier.

\subsection{Peer-to-Peer Marketing}

Peer-to-peer women-led delivery models show particular promise, as they can overcome several behavioural change challenges simultaneously. In such a model, women sell to others in their social network, either physically to friends and family or virtually via social media. Whilst many people may be sceptical of messages disseminated via mainstream media, peer-to-peer marketing enables consumers to receive these same messages from someone they trust. Furthermore, as sales agents are in regular contact with their network, live cooking demonstrations and after-sales service are much easier to deliver in peer-to-peer rather than centralised marketing models. Live cooking demonstrations can facilitate initial purchases, whilst after-sales service (e.g., from sourcing spare pressure valves for EPCs to offering advice on the best technique for cooking ugali with an induction stove) can enable sustained adoption. When combined with revolving funds, such as women's savings groups, peer-to-peer marketing strategies can also address the high upfront cost challenge.

A great example of this holistic approach is Bidhaa Sasa [52], who sells various products to women's savings groups in Western Kenya. The groups are coordinated by leaders, who perform a similar role to sales agents. Leaders can demonstrate products to the group, who can then decide which they want to buy. A revolving fund allows group members to purchase items in turn and pay back the cost over time. LPG stoves are their most popular product, however recent trials with EPCs amongst their grid-connected customers have shown there is a high demand for this new product when it is demonstrated by people they trust.

Jikoni Magic [40] is a Kenyan social media brand selling EPCs to their followers via social media. They have produced a series of YouTube video recipes and Instagram stories that have excited their followers enough for them to want to try these new devices themselves. They have established trust with their followers who have cooked their recipes before, so many also trust their advice enough to see the value in this new appliance, and are, therefore, willing to purchase directly from them.

\subsection{Consumer Finance for eCooking Appliances}

Even after people are convinced that food cooked with electricity is delicious and affordable, the upfront cost of the appliances is still a major barrier for many. Several MECS partners are trialling consumer financing mechanisms to break down the high upfront cost of eCooking appliances.

iDE Cambodia's induction stove [52] integrates PAYC hardware into the appliance. Although other appliance manufacturers and distributors will soon follow suit, independent PAYG providers, such as Angaza, could facilitate wider usage of PAYG in the emerging eCooking sector by developing interoperable PAYC technology. This would consist of hardware that could be integrated into any cooking appliance that would connect to a cloud-based payment platform.

In Uganda, EnerGrow have simplified the repayment process for consumers by establishing a partnership with Umeme for utility-enabled appliance financing. Brokering 
similar partnerships in other countries with asset-financing companies who are willing to take on the credit risk could offer an attractive solution for utility companies who are reluctant to take on this risk themselves.

Revolving funds are another attractive option, as many already exist, however the major challenge is how to tap into them. In Kenya, Bidhaa Sasa have used this model to sell EPCs to women's savings groups, and Kenya Power are hoping to extend their 'stima loan' (electricity loan) concept from connection fees to eCooking appliances. Jikoni Magic has engaged with a variety of revolving funds in Kenya, such as chamas (women's savings groups) and SACCOs (savings and cooperatives). Sharing the lessons from these engagements and distilling the findings for key archetypes of revolving funds could support others to forge similar partnerships.

Mini-grid companies are often much more dynamic than utilities, due to their smaller size and closer relationship with their customers, meaning that it can be easier for them to trial innovations, such as on-bill financing and dedicated cooking tariffs. Many minigrid developers already use smart metering, which can enable them to implement new tariffs and on-bill financing mechanisms with selected customers relatively easily. This is even more important for them, as existing expenditures in the peri-urban and rural areas where mini-grids are typically established are often much lower than typical urban utility customers. In contrast, tariffs, in particular, solar-hybrid mini-grid tariffs, are often many times higher than utilities. As a result, experimenting with carbon finance and other forms of Results Based Financing (RBF) that can reduce the tariff could make cooking much more attractive to consumers if it can be demonstrated to financiers that subsidised electricity is being used for cooking. Smart-metering at the household level can provide some evidence, but appliance-level monitoring could offer much greater assurances to financiers.

\subsection{How Does eCooking Stack up to ICS and LPG?}

Table 4 compares eCooking across each of Puzzolo et al.'s [14] seven domains. Many of the factors are important for all three types of fuel/energy, however the order is different. Impacts on time are particularly important for eCooking, highlighting the value that cooks place on reducing cooking times and multitasking. Socio-economic status is the most relevant for electricity, highlighting its aspirational nature, but also the challenge in making it accessible and affordable to low-income households. Smoke, health and safety; stove costs and subsidies; and regulation certification and standardisation are equally important for all three. Demand creation ranks highest for both eCooking and ICS, indicating that awareness of both technologies is currently low. Finally, user training is most important for electricity, highlighting the need to help users over the learning curve with energy-efficient appliances, such as EPCs.

Table 4. Comparison of factors influencing the uptake of ICS, LPG and electricity showing the three most important factors in each domain, identified by the number of studies mentioning each factor.

\begin{tabular}{|c|c|c|c|}
\hline & Improved Cookstoves (ICS) & $L P G$ & Electricity \\
\hline $\begin{array}{c}\text { D1-Fuel and technology } \\
\text { characteristics }\end{array}$ & $\begin{array}{c}\text { Fuel savings } \\
\text { Impacts on time } \\
\text { Design requirements }\end{array}$ & $\begin{array}{l}\text { Safety issues } \\
\text { Fuel savings } \\
\text { Impacts on time }\end{array}$ & $\begin{array}{l}\text { Impacts on time } \\
\text { Fuel requirements } \\
\text { Fuel savings }\end{array}$ \\
\hline $\begin{array}{l}\text { D2-Household and setting } \\
\text { characteristics }\end{array}$ & $\begin{array}{c}\text { Stacking } \\
\text { Socio-economic status } \\
\text { Education }\end{array}$ & $\begin{array}{l}\text { Stacking } \\
\text { Geography and climate } \\
\text { Socio-economic status }\end{array}$ & $\begin{array}{l}\text { Socio-economic status } \\
\text { Stacking } \\
\text { House ownership and } \\
\text { structure }\end{array}$ \\
\hline D3-Knowledge and perceptions & $\begin{array}{l}\text { Smoke, health and safety } \\
\text { Cleanliness and home } \\
\text { improvement } \\
\text { Social influence }\end{array}$ & $\begin{array}{l}\text { Smoke, health and safety } \\
\text { Tradition and culture } \\
\text { Perceived benefit }\end{array}$ & $\begin{array}{c}\text { Smoke, health and safety } \\
\text { Perceived benefit } \\
\text { Tradition and culture }\end{array}$ \\
\hline
\end{tabular}


Table 4. Cont.

\begin{tabular}{|c|c|c|c|}
\hline & Improved Cookstoves (ICS) & $L P G$ & Electricity \\
\hline $\begin{array}{l}\text { D4-Financial, tax and subsidy } \\
\text { aspects }\end{array}$ & $\begin{array}{l}\text { Stove costs and subsidies } \\
\text { Payment modalities } \\
\text { Programme subsidies }\end{array}$ & $\begin{array}{c}\text { Stove costs and subsidies } \\
\text { Fuel cost and subsidies } \\
\text { Payment modalities }\end{array}$ & $\begin{array}{l}\text { Stove costs and subsidies } \\
\text { Payment modalities } \\
\text { Fuel cost and subsidies }\end{array}$ \\
\hline D5-Market development & $\begin{array}{c}\text { Demand creation } \\
\text { Business and sales approach } \\
\text { Supply chain }\end{array}$ & $\begin{array}{c}\text { Supply chain } \\
\text { Demand creation } \\
\text { Business and sales approach }\end{array}$ & $\begin{array}{l}\text { Demand creation } \\
\text { Supply chain } \\
\text { Business and sales approach }\end{array}$ \\
\hline $\begin{array}{l}\text { D6-Regulation, legislation and } \\
\text { standards }\end{array}$ & $\begin{array}{l}\text { Regulation certification and } \\
\text { standardisation } \\
\text { Enforcement mechanism }\end{array}$ & $\begin{array}{l}\text { Regulation certification and } \\
\text { standardisation } \\
\text { Enforcement mechanism }\end{array}$ & $\begin{array}{l}\text { Regulation certification and } \\
\text { standardisation Enforcement } \\
\text { mechanisms }\end{array}$ \\
\hline $\begin{array}{c}\text { D7-Programmatic and policy } \\
\text { mechanisms }\end{array}$ & $\begin{array}{l}\text { Construction and installation } \\
\text { Monitoring and quality } \\
\text { control User training }\end{array}$ & $\begin{array}{l}\text { Institutional arrangements } \\
\text { User training } \\
\text { Monitoring and quality } \\
\text { control }\end{array}$ & $\begin{array}{l}\text { User training post-acquisition } \\
\text { support } \\
\text { Monitoring and quality } \\
\text { control }\end{array}$ \\
\hline
\end{tabular}

\subsection{Embracing Stacking to Encourage Exclusive Use of Electricity (and Other Clean Fuels) in the Kitchen}

The stacking of cooking devices is almost universal across cultures; however, this is both a challenge and an opportunity. If a household's fuel stack includes polluting fuels, then many of the benefits of adopting eCooking, in particular, the health benefits, are forfeited. However, there are several practical approaches to stacking that can enable households to transition away from biomass:

- Clean fuel stacking - by promoting complementary clean cooking technologies (e.g., SCODE's EPC and LPG pilots in Kenya), the likelihood of households meeting all of their cooking needs with clean fuels is greatly increased.

- Appliance stacking - a similar logic applies to the promotion of complementary electric cooking appliances (e.g., EarthSpark's EPC/induction pilots in Haiti [31]).

- Understand and address the drivers of continued biomass use-this develops targeted BCTs to nudge cooks away from biomass and towards a completely clean fuel/appliance stack (e.g., UCL's application of the Behaviour Change Wheel [23] with PAYG LPG customers [84]).

\section{Conclusions}

This paper has explored the challenges and opportunities in the emerging field of eCooking from a consumer perspective. It has highlighted the behavioural change barriers, as well as the drivers, drawing on established theory and BCTs to identify viable strategies that might facilitate the wider adoption of eCooking. The evidence gathered suggests that to achieve the intended development impacts, strategies must extend beyond the initial adoption to the sustained use of these new appliances, whilst gradually nudging cooks towards the exclusive use of electricity (and other clean fuels) and completely away from biomass.

The evidence shows that the uptake of eCooking can be hindered by (often false) perceptions around cost, taste and safety, the high cost and steep learning curve for new energy-efficient appliances, the lack of awareness/availability/after-sales service for energy-efficient appliances and the reluctance of male decision-makers to authorise appliance purchases. However, it also shows that the convenience and potential cost savings offered by energy-efficient appliances can offer an aspirational cooking experience and that uptake could be driven forward rapidly by urbanisation and changing lifestyles.

Tailored intervention strategies are necessary to reach the different segments of society, considering their unique needs and idiosyncrasies. Adoption is a process, and we have to acknowledge the different strategies households use to cope with uncertainty (in relation to income, electricity supply, etc.), in particular, the stacking of fuels and appliances. 
Behavioural change is key to the transition process, and sustainable shifts in behaviour happen only when both cooking device usage patterns and associated perceptions are tracked, and interventions refined over long timeframes.

This paper has highlighted several delivery approaches for eCooking that show strong potential to tackle a range of behaviour change challenges. These include peer-to-peer marketing; engaging men as both decision-makers and potential cooks; PAYC (Pay as You Cook), and utility-enabled financing to break down the high upfront cost of energy-efficient appliances; embracing stacking and designing immersive experiences that allow consumers to trial eCooking at home with limited financial risk.

Looking forward, this paper has highlighted several research gaps in the emerging field of eCooking. On the theoretical front, the Behaviour Change Wheel [31], Diffusion of Innovations and the Theory of Planned Behaviour can offer deeper insight into the motivations behind cooking behaviour. There is a need to dive deeper into key issues, such as gendered decision making, energy poverty and energy justice. By understanding and aligning with consumer aspirations, more effective interventions can be developed by combining a selection of targeted BCTs designed to nudge cooks away from biomass and towards a completely clean appliance/fuel stack [23].

Compared to other clean cooking and electrification technologies, eCooking is still at a relatively nascent stage. As a result, much of this initial experimentation with eCooking has involved relatively small-scale pilot projects $(n<100)$ in a limited set of countries (primarily within the Commonwealth, due to FCDO funding for the MECS programme and the preceding projects). To achieve transformative change on a global scale, there is a need to explore the opportunities in a broader range of geographies, in particular, to study the transition pathways of industrialised nations where eCooking has already broken through into the mainstream. Experimentation at scale with more robust methodologies (e.g., Randomised Control Trials) and tapping into larger scale sources of finance (e.g., Results Based Financing) will also be necessary to verify the initial findings from these early studies and provide a stronger evidence base for eCooking. Scenario modelling can then be used to inform policy-makers of a range of regulatory measures that could facilitate the uptake of eCooking and evaluate the likely impacts of widespread adoption and sustained use.

Author Contributions: Conceptualization, J.L.; methodology, J.L., B.M., V.C., K.T.; investigation, J.L., B.M., V.C., K.T.; writing—original draft preparation, J.L., B.M., V.C., K.T.; writing—review and editing, J.L., B.M., V.C., K.T. All authors have read and agreed to the published version of the manuscript.

Funding: This paper was made open access through funding from the MECS programme (GB-GOV1-300123), a UKAid funded programme led by Loughborough University. The opinions expressed do not necessarily reflect the opinions of the UK Government. The research that led to the programme and supports the argument in the paper was funded by EPSRC (EP/L022311/1) and InnovateUK (132724) with matching funds by Gamos Ltd., who also invested in the research as a public good.

Institutional Review Board Statement: Not applicable.

Informed Consent Statement: Not applicable.

Data Availability Statement: Available on request.

Conflicts of Interest: The authors declare no conflict of interest.

\section{Appendix A. Behaviour Change Techniques and Theoretical Frameworks}

This section presents a review of the Behavioural Change Techniques (BCTs) and theoretical frameworks that are most relevant to eCooking. There is increasing realisation that cooking practices, as an activity steeped in culture, are difficult to change by offering different technological options without a strategy targeting behaviour change. As highlighted by the authors of [14], transitioning households to cleaner cooking involves adopting new practices, whilst letting go of old ones, requiring changes in behaviour on 
behalf of the cook, as well as other household members, such as financial decision-makers, who are often male breadwinners.

A key step in addressing the behavioural challenges at the household level is a proper conceptualisation of the problem and the interventions needed to effect a certain change in behaviour. As such, understanding behaviour change elements and processes have been a subject of much interest to researchers resulting in the development of techniques, models and theories in an attempt to bridge the gap in understanding of behaviour in many contexts. Behaviour change models/theories present a framework to group, analyse, and characterise interventions that affect a target behaviour. They span both the internal (e.g., personal preferences for a particular flavour) and external (e.g., current market price of a particular appliance) factors.

\section{Appendix A.1. Theoretical Frameworks for Behaviour Change}

At a more aggregated level, models/theories provide a high-level framework under which specific techniques can be designed. Several frameworks and theories exist, and those mentioned here are not meant to be exhaustive, but relevant to the discussion of behaviour change relating to technology adoption/diffusion in the cooking context.

\section{Appendix A.2. COM-B and the Behaviour Change Wheel (BCW)}

The Behaviour Change Wheel (BCW) [23] is a comprehensive framework that seeks to understand the conditions within and outside the individual (social and physical environment) with respect to a specific target behaviour (Figure A1). It consists of an inner circle (which embeds the COM-B framework), an intermediate circle of intervention functions (education, training, persuasion, etc.) and an outer circle made up of policy categories. The inner circle postulates that behaviour change needs to be approached using three different components: Capability, Opportunity and Motivation (COM-B). Capability refers to the individuals psychological and physical capacity to engage in the change required. This encompasses the knowledge about why certain fuel options are detrimental and what options are available to switch. Motivation speaks to the brain process that drives or direct behaviour, including conscious and unconscious decision making like emotional reactions, habits etc. Here again, this can refer to the willingness to consider other clean cooking options when offered. Opportunity refers of the physical and social environment that facilitate the undertaking of the new behaviour, and this could include government commitment to promote or ban the use of certain fuels or influences in one's social or peer network. Surrounding the inner COM-B system, the BCW encompasses nine (9) intervention functions and seven (7) policy categories hinting at the importance of both individual level and policy level factors in behaviour change.

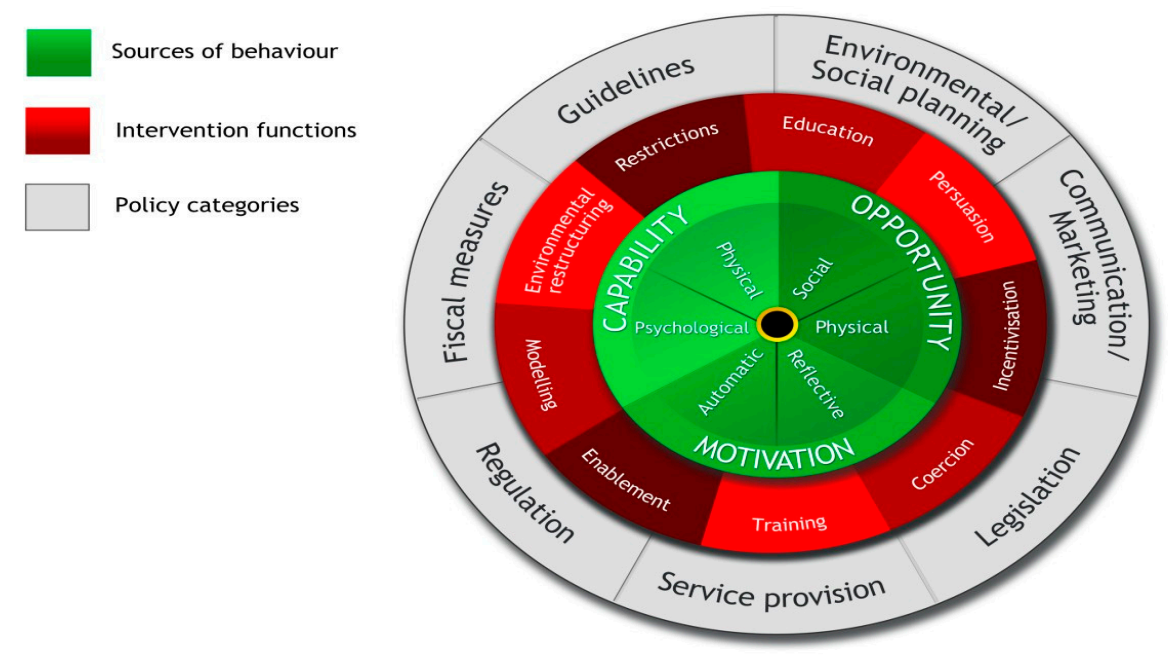

Figure A1. The behaviour change wheel [23]. 


\section{Appendix A.3. Theories of Reasoned Action and Planned Behaviour (TRA and TPB)}

The Theories of Reasoned Action (TRA) [23] and Planned Behaviour (TPB) [21] deconstruct the individual motivational factors that determine the likelihood of a person performing a certain behaviour. The TPB, an extension of the TRA (see Figure A2), postulates that the determinants of a particular behaviour hinge on one's behavioural intention and perceived behavioural control, which is the perception that the target behaviour is easy or difficult. Based on this, different individuals will respond at different times to uptake of a certain behaviour.

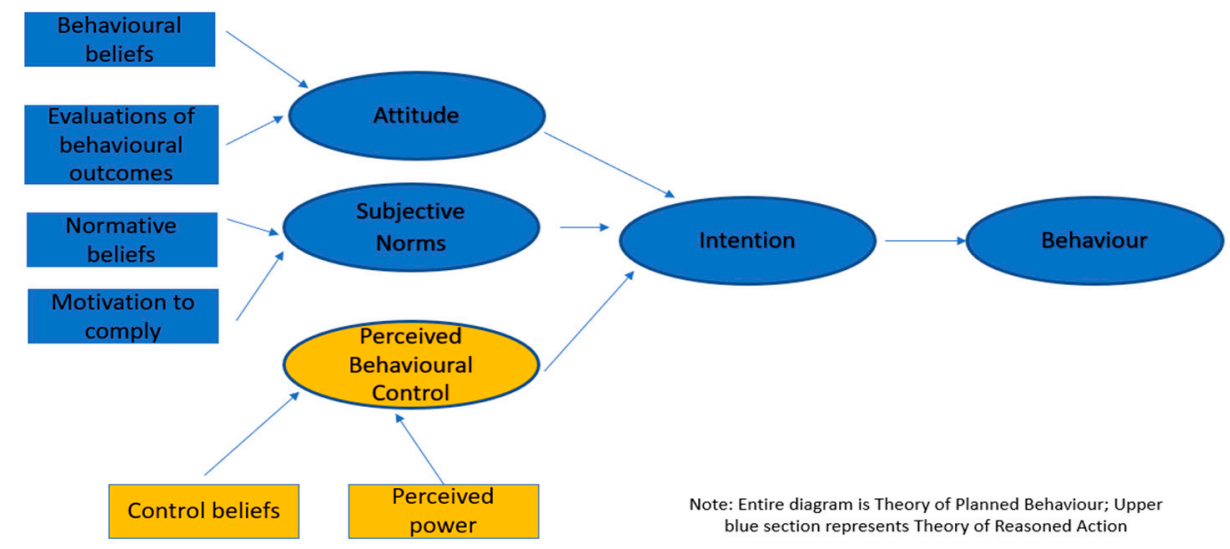

Figure A2. The interrelationship between TRA and TPB. Adapted from the work by the authors of [22].

\section{Appendix A.4. Rogers' Diffusion of Innovation Theory}

This theory demonstrates the process through which innovation spreads (or diffuses) throughout society over time. Rogers [22] proposes four main elements that influence the diffusion of an idea or change. These are:

1. The innovation (idea or technology perceived as new by the individual);

2. Communication channels (how information gets from one individual to another);

3. Time;

4. The social system (individuals, informal groups, organisations or sub-systems)

Rogers also grouped adopters into five categories: Innovators, early adopters, early majority, late majority and laggards (see Figure A3). Innovators characterised as seekers of new information, having the ability to cope with higher levels of uncertainty and exposure to greater networks than the local network provides. Conversely, members of the late majority are likely to be of low social status, making use of fewer media channels, but relying heavily on interpersonal channels. This shows that there are different attitudes towards innovation, and a thorough assessment of the market is necessary to identify who to target for better impact at specific times.

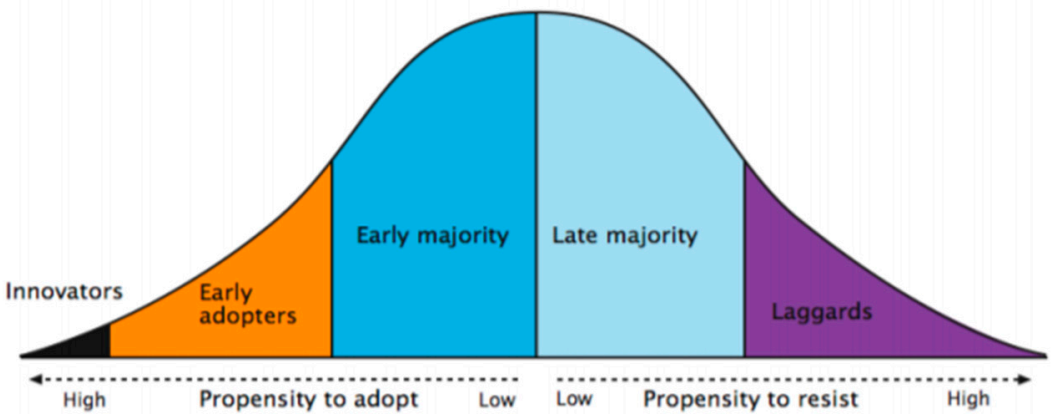

Figure A3. Rogers' adoption categories in Diffusion of Innovation Theory. Adapted from the work by the authors of [20]. 
Rogers describes the process that leads to adoption in five stages:

1. Knowledge or Awareness: Initial exposure to the innovation;

2. Persuasion or Interest: Initial interest and quest for more information;

3. Decision or Evaluation: Consideration of the innovation's potential additional value;

4. Implementation or Trial: Experiencing the innovation by testing it out;

5. Confirmation or Adoption: Decision on whether to continue using the innovation.

\section{Appendix A.5. Behaviour Change Techniques (BCTs)}

BCTs are active components within an intervention that catalyses behaviour change [20]. They are regarded as the building blocks for behaviour change interventions. Goodwin et al. regard BCTs as activities that can be deployed at several points along the value chain, whether at the design, production, finance, or maintenance stage (see Table A1).

Table A1. Behaviour change techniques definitions and examples. Adapted from [20].

\begin{tabular}{|c|c|c|}
\hline BCT & Description & Example \\
\hline Reward and threat & $\begin{array}{c}\text { Makes the adoption of new behaviours seem attractive, } \\
\text { or the failure to adopt them seem threatening. Linked } \\
\text { to the concept of value exchange, i.e., what desirable } \\
\text { outcome would the audience receive for their } \\
\text { compliance, or what undesirable outcome would they } \\
\text { avoid. }\end{array}$ & $\begin{array}{l}\text { Incentives for } \\
\text { households to buy } \\
\text { appliances }\end{array}$ \\
\hline Shaping knowledge & $\begin{array}{l}\text { Helps people to understand what desirable behaviours } \\
\text { are, how to perform them, and where to acquire the } \\
\text { necessary technologies and skills. }\end{array}$ & $\begin{array}{l}\text { Radio announcements } \\
\text { on appliance } \\
\text { availability }\end{array}$ \\
\hline $\begin{array}{l}\text { Changing the physical } \\
\text { environment }\end{array}$ & $\begin{array}{c}\text { Structural changes to the surrounding environment so } \\
\text { that a new behaviour is easier to sustain with } \\
\text { supportive triggers. }\end{array}$ & $\begin{array}{l}\text { Construction of a new } \\
\text { indoor kitchen area }\end{array}$ \\
\hline Social support & $\begin{array}{l}\text { Providing resources and facilitating influence. Seeding } \\
\text { a new behaviour with a trusted person or group helps } \\
\text { ensure the new behaviour appears desirable and starts } \\
\text { to become the norm, leading others to want to emulate } \\
\text { and model it. }\end{array}$ & $\begin{array}{l}\text { Friends / family acting } \\
\text { as sales agents in a } \\
\text { peer-to-peer } \\
\text { distribution model }\end{array}$ \\
\hline $\begin{array}{l}\text { Goals, planning and } \\
\text { monitoring }\end{array}$ & $\begin{array}{c}\text { Unearthing aspirations, ambitions and intentions and } \\
\text { reframing the new behaviour as a way of achieving } \\
\text { these goals. }\end{array}$ & $\begin{array}{l}\text { Energy monitoring } \\
\text { devices that show how } \\
\text { much you're saving } \\
\text { each time you cook }\end{array}$ \\
\hline Comparisons & $\begin{array}{l}\text { Offering a selection of options and/or compare the } \\
\text { innovation with current practice. }\end{array}$ & $\begin{array}{l}\text { Offering a variety of } \\
\text { models of electric } \\
\text { appliance }\end{array}$ \\
\hline Identity and self-belief & $\begin{array}{l}\text { Targets actual or aspirational societal roles by } \\
\text { exploring how we perceive ourselves, how we are } \\
\text { perceived, and therefore, how we think and act to } \\
\text { increase self-efficacy and build momentum towards a } \\
\text { desire to change behaviour. }\end{array}$ & $\begin{array}{l}\text { Empowering women as } \\
\text { entrepreneurs }\end{array}$ \\
\hline Regulation & $\begin{array}{l}\text { Regulatory mechanisms can provide a measure of } \\
\text { enforcement (e.g., bans or industry standards) or } \\
\text { persuasion (e.g., incentives or tax exemptions). }\end{array}$ & $\begin{array}{l}\text { Lifeline tariffs designed } \\
\text { for cooking }\end{array}$ \\
\hline
\end{tabular}

\section{References}

1. ESMAP. Tracking SDG7I Progress towards Sustainable Energy; World Bank Group: Washington, DC, USA, 2020.

2. WHO. Household Fuel Combustion-WHO Guidelines for Indoor Air Quality; World Health Organisaton: Geneva, Switzerland, 2014.

3. Batchelor, S.; Brown, E.; Scott, N.; Leary, J. Two Birds, One Stone-Reframing Cooking Energy Policies in Africa and Asia. Energies 2019, 12, 1591. [CrossRef]

4. ESMAP. Cooking with Electricity: A Cost Perspective; World Bank Group: Washington, DC, USA, 2020.

5. Couture, T.; Jacobs, D. Beyond Fire: How to Achieve Electric Cooking; HIVOS \& World Future Council: The Hague, The Netherlands, 2019. 
6. Leary, J.; Fodio Todd, J.; Batchelor, S.; Chepkurui, K.; Chepkemoi, M.; Numi, A.; Hanlin, R.; Scott, N.; Brown, E. The Kenya eCookBook: Beans \& Cereals Edition. MECS, ACTS, Loughborough University, Gamos and University of Sussex Supported by EPSRC and UK Aid (DfID). 2019. Available online: www.MECS.org.uk (accessed on 13 July 2021).

7. TaTEDO. The Tanzania eCookbook; Tanzania Traditional Energy Development Organisation: Dar es Salaam, Tanzania, 2020; ISBN 9789976568400.

8. Moutinho, L. Consumer Behaviour in Tourism. Eur. J. Mark. 1987, 21, 5-44. [CrossRef]

9. Faiers, A.; Cook, M.; Neame, C. Towards a contemporary approach for understanding consumer behaviour in the context of domestic energy use. Energy Policy 2007, 35, 4381-4390. [CrossRef]

10. Cattaneo, C. Internal and external barriers to energy efficiency: Which role for policy interventions? Energy Effic. 2019, 12, 1293-1311. [CrossRef]

11. Vigolo, V.; Sallaku, R.; Testa, F. Sustainability Drivers and Barriers to Clean Cooking: A Systematic Literature Review from a Consumer Behavior Perspective. Sustainability 2018, 10, 4322. [CrossRef]

12. Brown, E.; Sumanik-Leary, J. A Review of the Behavioural Change Challenges Facing a Proposed Solar and Battery Electric Cooking Concept; Prepared at the Request of the UK Department for International Development; Evidence on Demand: London, UK, 2015.

13. Quinn, A.K.; Bruce, N.; Puzzolo, E.; Dickinson, K.; Sturke, R.; Jack, D.W.; Mehta, S.; Shankar, A.; Sherr, K.; Rosenthal, J.P. An analysis of efforts to scale up clean household energy for cooking around the world. Energy Sustain. Dev. 2018, 46, 1-10. [CrossRef]

14. Puzzolo, E.; Stanistreet, D.; Pope, D.; Bruce, N.; Rehfuess, E. Systematic Review Factors Influencing the Large-Scale Uptake by Households of Cleaner and More Efficient Household Energy Technologies; EPPI-Centre, Social Science Research Unit, Institute of Education, University of London: London, UK, 2013.

15. IEA; International Renewable Energy Agency; United Nations Statistics Division; The World Bank; World Health Organization. The Energy Progress Report; IEA: Paris, France, 2019.

16. Batchelor, S.; Leary, J.; Sago, S.; Minja, A.; Chepkurui, K.; Sawe, E.; Shuma, J.; Scott, N. Opportunities \& Challenges for eCook Tanzania-October 2019 Working Paper. TaTEDO, Loughborough University, University of Surrey \& Gamos Ltd. Supported by Innovate UK, UK Aid (DfID) \& Gamos Ltd. 2019. Available online: www.MECS.org.uk (accessed on 13 July 2021).

17. Scott, N.; Leary, J.; Hlaing, W.W.; Myint, A.; Sane, S.; Win, P.P.; Phyu, T.M.; Moe, E.T.; Batchelor, S.; Vaghela, D.; et al. Opportunities \& Challenges for eCook in Myanmar-October 2019 Working Paper. REAM, Loughborough University, University of Surrey \& Gamos Ltd. Supported by Innovate UK, UK Aid \& Gamos Ltd. 2019. Available online: www.MECS.org.uk (accessed on 13 July 2021).

18. Leary, J.; Scott, N.; Serenje, N.; Mwila, F.; Batchelor, S.; Leach, M.; Brown, E.; Yamba, F. Opportunities \& Challenges for eCook in Zambia-October 2019 Working Paper. CEEEZ, Loughborough University, University of Surrey \& Gamos Ltd. Supported by Innovate UK, UK Aid \& Gamos Ltd. 2019. Available online: www.MECS.org.uk (accessed on 13 July 2021).

19. Leary, J.; Scott, N.; Numi, A.; Chepkurui, K.; Hanlin, R.; Chepkemoi, M.; Batchelor, S.; Leach, M.; Brown, E.; Batchelor, S.; et al. eCook Kenya Cooking Diaries-September 2019 Working Paper. ACTS, Gamos Ltd., University of Sussex and UIU Supported by UK Aid, EPSRC, RCUK \& DECC. 2019. Available online: www.MECS.org.uk (accessed on 13 July 2021).

20. Rogers, E.M. Diffusion of Innovations; Free Press: New York, NY, USA, 2003; ISBN 07432220919780743222099.

21. Fishbein, M. A theory of reasoned action: Some applications and implications. Neb. Symp. Motiv. 1979, $27,65-116$.

22. Ajzen, I. The Theory of Planned Behavior. Organ. Behav. Hum. Decis. Process. 1991, 50, 179-211. [CrossRef]

23. Michie, S.; van Stralen, M.; West, R. The behaviour change wheel: A new method for characterising and designing behaviour change interventions Susan. Implement. Sci. 2011, 6, 1-12. [CrossRef]

24. Goodwin, N.J.; O'Farrell, S.E.; Jagoe, K.; Rouse, J.; Roma, E.; Biran, A.; Finkelstein, E.A. Use of behavior change techniques in clean cooking interventions: A review of the evidence and scorecard of effectiveness. J. Health Commun. 2015, 20, 43-54. [CrossRef]

25. Gius, G.; Walker, M.; Li, A.; Adams, N.J.; Van Buskirk, R.; Schwartz, P. Hot diodes!: Dirt cheap cooking and electricity for the global poor? Dev. Eng. 2019, 4, 100044. [CrossRef]

26. Watkins, T.; Arroyo, P.; Perry, R.; Wang, R.; Arriaga, O.; Fleming, M.; O’Day, C.; Stone, I.; Sekerak, J.; Mast, D.; et al. Insulated Solar Electric Cooking-Tomorrow's healthy affordable stoves? Dev. Eng. 2017, 2, 47-52. [CrossRef]

27. Van Buskirk, R.; Schwartz, P. Solar Electricity Access for Rural Africans at Less than $\$ 0.02 / \mathrm{kWh}$ by 2030? 2019. Available online: https:/ /www.researchgate.net/publication/331262290_Solar_electricity_access_for_rural_Africans_at_less_than_002kWh_ by_2030 (accessed on 13 July 2021).

28. Jacobs, D.; Schurig, S.; Matser, E.; Leidreiter, A.; García, I. Beyond Fire: How to Achieve Sustainable Cooking; Hivos: The Hague, The Netherlands, 2016.

29. Leary, J.; Scott, N.; Sago, S.; Minja, A.; Batchelor, B.; Chepkurui, K.; Sawe, E.; Leach, M.; Brown, E. eCook Tanzania Cooking Diaries-October 2019 Working Paper. REAM, Loughborough University, University of Surrey \& Gamos Ltd. Supported by Innovate UK, UK Aid (DfID) \& Gamos Ltd. 2019. Available online: www.MECS.org.uk (accessed on 13 July 2021).

30. CREEC. Cooking with Electricity in Uganda: Barriers and Opportunities; MECS Working Paper; CREEC: Kampala, Uganda, 2020.

31. Bilich, A.; Sanassee, W.; Archambault, A. On-and off-(Micro) Grid PV Electric Cooking: Field Data for Integrated Energy Access in Haiti; MECS Working Paper; EarthSpark International: Les Anglais, Haiti, 2021. 
32. Leary, J.; Win, P.; Myint, A.; Sane, S.; Win, P.; Phyu, T.; Moe, E.; Htay, T.; Batchelor, S.; Vaghela, D.; et al. eCook Myanmar Focus Group Discussions-October 2019 Working Paper. REAM, Loughborough University, University of Surrey \& Gamos Ltd. Supported by Innovate UK, UK Aid (DfID) \& Gamos Ltd. 2019. Available online: www.MECS.org.uk (accessed on 13 July 2021).

33. Leary, J.; Mwila, F.; Serenje, N.; Yamba, F.; Batchelor, S.; Brown, E.; Leach, M.; Scott, N. eCook Zambia Design Challenge Workshop Report. CEEEZ, Loughborough University, University of Surrey \& Gamos Ltd. Supported by Innovate UK, UK Aid \& Gamos Ltd. 2019. Available online: www.MECS.org.uk (accessed on 13 July 2021).

34. Brown, E.; Leary, J.; Davies, G.; Batchelor, S.; Scott, N. eCook: What behavioural challenges await this potentially transformative concept? Sustain. Energy Technol. Assess. 2017, 22, 106-115. [CrossRef]

35. Leary, J.; Scott, N.; Serenje, N.; Mwila, F.; Batchelor, S.; Leach, M.; Brown, E.; Yamba, F. eCook Zambia Cooking Diaries-October 2019 Working Paper. CEEEZ, Loughborough University, University of Surrey \& Gamos Ltd. Supported by Innovate UK, UK Aid \& Gamos Ltd. 2019. Available online: www.MECS.org.uk (accessed on 13 July 2021).

36. Clements, W.; Silwal, K.; Pandit, S.; Leary, J.; Gautam, B.; Williamson, S.; Tran, A.; Harper, P. Unlocking electric cooking on Nepali micro-hydropower mini-grids. Energy Sustain. Dev. 2020, 57, 119-131. [CrossRef]

37. Leary, J.; Scott, N.; Hlaing, W.W.; Myint, A.; Sane, S.; Win, P.P.; Phyu, T.M.; Moe, E.T.; Htay, T.; Batchelor, S.; et al. eCook Myanmar Cooking Diaries-October 2019 Working Paper. REAM, Loughborough University, University of Surrey \& Gamos Ltd. Supported by Innovate UK, UK Aid (DfID) \& Gamos Ltd. 2019. Available online: www.MECS.org.uk (accessed on 13 July 2021).

38. Njobvu, C.; Serenje, N.; Price, M.; Yamba, F. MECS Kitchen Laboratory-Zambia; MECS Working Paper; CEEEZ: Lusaka, Zambia, 2021.

39. Global LEAP. Global LEAP Awards Electric Pressure Cooker Competition. 2020. Available online: https://globalleapawards.org/ electric-pressure-cookers (accessed on 10 May 2020).

40. Jikoni Magic. MECS TRIID-Smart Cooking Solutions; MECS Working Paper; Jikoni Magic: Nairobi, Kenya, 2020.

41. Bidhaa Sasa. Women-to-Women Distribution Model to Increase Adoption of Clean Cooking Methods by Low Income Women in Rural Kenya; MECS Working Paper; Bidhaa Sasa: Webuye, Kenya, 2020.

42. CalPoly. Thermal Storage with Phase Change Materials; MECS Working Paper; CalPoly: San Luis Obispo, CA, USA, 2020.

43. ServedOnSalt. Prototype Development of Cooker with Integrated Thermochemical Energy Storage; MECS Working Paper; ServedOnSalt: Copenhagen, Denmark, 2020.

44. Kachione. Customizing Malawi-Made Solar Electric Cooking Technology and Business Models to Provide Access to Very Low Income Villagers; MECS Working Paper; Kachione: Chichiri, Malawi, 2020.

45. PEEDA. MECS-TRIID Project Report-Assessing Electric Cooking Potential in Micro Hydropower Microgrids in Nepal; PEEDA: Kathmandu, Nepal, 2020.

46. Cowan, B. Identification and Demonstration of Selected Energy Best Practices for Low-Income Urban Communities in South Africa; Alleviation of Poverty Through the Provision of Local Energy Services (APPLES); Energy Research Centre, University of Cape Town: Cape Town, South Africa, 2008.

47. Leary, J.; Batchelor, S.; Scott, N. Cooking Diaries 3.0 Protocols; MECS Working Paper; Gamos: Reading, UK, 2019.

48. ESMAP. What Drives the Transition to Modern Energy Cooking Services? ESMAP Technical Report 015/21; World Bank Group: Wahington, DC, USA, 2021.

49. GenDev. Identifying Drivers and Barriers to Sustained Adoption of LPG as Clean Cooking Energy: Applying Lessons from India's LPG Programme to Nepal and Myanmar; MECS Working Paper; GenDev: Washington, DC, USA, 2020.

50. Slaski, X.; Thurber, M. Research Note: Cookstoves and Obstacles to Technology Adoption by the Poor; Freeman Spogli Institute for International Studies: Stanford, CA, USA, 2009.

51. Chepkurui, K.; Leary, J.; Minja, A.; Sago, S.; Batchelor, S.; Sawe, E.; Brown, E.; Leach, M.; Scott, N.; Shuma, J. eCook and Gender in Tanzania-March 2019 Final Report. TaTEDO, Loughborough University, University of Surrey \& Gamos Ltd. Supported by Innovate UK, UK Aid \& Gamos Ltd. 2019. Available online: https:/ / elstove.com/innovate-reports / (accessed on 13 July 2021).

52. Bansod, A.; Campos, N. MECS-TRIID Exploring Futures of Alternative Cooking in Cambodia; iDE Cambodia: Pnomh Penh, Cambodia, 2020; p. 122.

53. Mediae Shamba Shape Up. Available online: https:/ / shambashapeup.com/ (accessed on 26 May 2021).

54. Scott, N.; Jones, T.; Myanmar, S.B. Cooking Transitions: An analysis of Multi-Tier Framework Data for Insights into Transitions to Modern Energy Cooking; MECS Working Paper; Gamos: Reading, UK, 2020.

55. Scott, N.; Batchelor, S.; Jones, T. Exploring MECS User Personas; MECS Working Paper; Gamos: Reading, UK, 2019.

56. ESMAP. The State of Access to Modern Energy Cooking Services; World Bank Group: Washington, DC, USA, 2020.

57. Leary, J.; Serenje, N.; Mwila, F.; Batchelor, S.; Leach, M.; Brown, E.; Scott, N.; Yamba, F. eCook Zambia Focus Group Discussions Summary Report. CEEEZ, Loughborough University, University of Surrey \& Gamos Ltd. Supported by Innovate UK, UK Aid \& Gamos Ltd. 2019. Available online: www.MECS.org.uk (accessed on 13 July 2021).

58. Perrett, A. An Investigation into the Potential of Dc Solar-Powered Cook Stoves with Tanzanian Food Vendors; MECS Working Paper; Africa Power: Pretoria, South Africa, 2020.

59. Masera, O.R.; Saatkamp, B.D.; Kammen, D.M. From linear fuel switching to multiple cooking strategies: A critique and alternative to the energy ladder model. World Dev. 2000, 28, 2083-2103. [CrossRef]

60. Ruiz-Mercado, I.; Masera, O. Patterns of Stove Use in the Context of Fuel-Device Stacking: Rationale and Implications. Ecohealth 2015, 12, 42-56. [CrossRef] 
61. Troncoso, K. A Recipe for Developing Adoption and Impact Indices; Clean Cooking Alliance (CCA): Washington, DC, USA, 2014.

62. WHO. Burning Opportunity: Clean Household Energy for Health, Sustainable Development, and Wellbeing of Women and Children; World Health Organisation: Geneva, Switzerland, 2016.

63. Batchelor, S.; Brown, E.; Scott, N.; Leary, J. Experiences of Electric Pressure Cookers in East Africa. In Proceedings of the 10th International Conference on Energy Efficiency in Domestic Appliances and Lighting (EEDAL 19), Jinan, China, 6-8 November 2019; pp. 1-29.

64. A2EI. Clean Cooking Data Release-December 2020; Access to Energy Institute: Arusha, Tanzania, 2020.

65. Jones, T.; Scott, N.; Clements, A. A2EI Mini-Grid Cooking Diaries Data Analysis; MECS Working Paper; Gamos: Reading, UK, 2021.

66. Gould, C.F.; Schlesinger, S.B.; Molina, E.; Bejarano, M.L.; Valarezo, A.; Jack, D.W. Household fuel mixes in peri-urban and rural Ecuador: Explaining the context of LPG, patterns of continued firewood use, and the challenges of induction cooking. Energy Policy 2020, 136, 111053. [CrossRef] [PubMed]

67. Scott, N.; Leary, J.; Sago, S.; Minja, A.; Batchelor, S.; Chepkurui, K.; Sawe, E.; Leach, M.; Brown, E. eCook Tanzania Discrete Choice Modelling-October 2019 Working Paper. REAM, Loughborough University, University of Surrey \& Gamos Ltd. Supported by Innovate UK, UK Aid (DfID) \& Gamos Ltd. 2019. Available online: www.MECS.org.uk (accessed on 13 July 2021).

68. Leary, J.; Htay, T.; Hlaing, W.; Myint, A.; Sane, S.; Win, P.; Phyu, T.; Moe, E.; Batchelor, S.; Vaghela, D. eCook Myanmar Prototyping-October 2019 Working Paper. REAM, Loughborough University, University of Surrey \& Gamos Ltd. Supported by Innovate UK, UK Aid (DfID) \& Gamos Ltd. 2019. Available online: www.MECS.org.uk (accessed on 13 July 2021).

69. Batchelor, S.; Talukder, M.; Uddin, M.; Mondal, S.; Islam, S.; Redoy, R.; Hanlin, R.; Khan, M. Solar e-Cooking: A Proposition for Solar Home System Integrated Clean Cooking. Energies 2018, 11, 2933. [CrossRef]

70. Waldron, D.; Hacker, S. Electric Bankers-Utility-Enabled Finance in Sub-Saharan Africa; CGAP \& CLASP: Washington, DC, USA, 2020.

71. Gould, C.F.; Schlesinger, S.; Toasa, A.O.; Thurber, M.; Waters, W.F.; Graham, J.P.; Jack, D.W. Government policy, clean fuel access, and persistent fuel stacking in Ecuador. Energy Sustain. Dev. 2018, 46, 111-122. [CrossRef] [PubMed]

72. Troncoso, K.; da Silva, A.S. LPG fuel subsidies in Latin America and the use of solid fuels to cook. Energy Policy 2017, 107, 188-196. [CrossRef]

73. Leary, J.; Batchelor, S.; Leach, M.; Brown, E.; Alsop, A. eCook Global Market. Assessment. Where Will the Transition Take Place First? Implemented by Gamos, Loughborough University, University of Surrey. Supported by Innovate UK, UK Aid (DfID) \& Gamos Ltd. 2019. Available online: www.MECS.org.uk (accessed on 13 July 2021).

74. Bekker, B.; Eberhard, A.; Gaunt, T.; Marquard, A. South Africa's rapid electrification programme: Policy, institutional, planning, financing and technical innovations. Energy Policy 2008, 36, 3125-3137. [CrossRef]

75. Ledger, T. Broken Promises. Electricity Access for Low-Income Households: Good Policy Intentions, Bad Trade-offs and Unintended Consequences; PARI: Johannesburg, South Africa, 2019.

76. KPLC Pika na Power. Available online: https://www.facebook.com/PikaNaPower/ (accessed on 12 July 2019).

77. TaTEDO. MECS-TRIID Approach to Designing Delivery Models of Modern Energy Cooking Services in Tanzania (ADD-MECS-Ta); MECS Working Paper; TaTEDO: Dar es Salaam, Tanzania, 2020.

78. Huete-Alcocer, N. A literature review of word of mouth and electronic word of mouth: Implications for consumer behavior. Front. Physiol. 2017, 8, 1-4. [CrossRef] [PubMed]

79. EnDev Accelerating the off-Grid Appliance Market with RBF-e-Cooking and Energy Efficiency RBF Facility Webinar Series. 2020. Available online: https: / / endev.info/accelerating-the-off-grid-appliance-market-with-rbf-e-cooking-and-energy-efficiencyrbf-facility-webinar-series-2020/ (accessed on 26 May 2021).

80. Ockwell, D.; Byrne, R.; Chengo, V.; Onsongo, E.; Todd, J.F.; Atela, J. Transformative Innovations Start with the Social and Political, Not Technology Hardware and Finance: Lessons from Lighting Africa and MECS; MECS Briefing Note; University of Sussex: Brighton, UK, 2019.

81. Shittu, O.S.; Williams, I.D.; Shaw, P.J. Global E-waste management: Can WEEE make a difference? A review of e-waste trends, legislation, contemporary issues and future challenges. Waste Manag. 2021, 120, 549-563. [CrossRef] [PubMed]

82. Boardman, B. New directions for household energy efficiency: Evidence from the UK. Energy Policy 2004, 32, 1921-1933. [CrossRef]

83. Schubert, R.; Stadelmann, M. Energy-using durables-why consumers refrain from economically optimal choices. Front. Energy Res. 2015, 3, 1-13. [CrossRef]

84. Perros, T.; Buettner, P. MECS Behaviour Change Project Report Understanding Pay-As-You-Go LPG Customer Behaviour; MECS Working Paper; UCL: London, UK, 2021. 